\title{
Intrinsic TGF- $\beta$ signaling promotes age-dependent CD8+ T cell polyfunctionality attrition
}

\author{
Rajarshi Bhadra,1,2 Magali M. Moretto, ${ }^{1}$ Julio C. Castillo, ${ }^{3}$ \\ Constantinos Petrovas, 4 Sara Ferrando-Martinez,5,6 Upasana Shokal, ${ }^{3}$ \\ Manuel Leal, ${ }^{5}$ Richard A. Koup, ${ }^{4}$ Ioannis Eleftherianos, ${ }^{3}$ and Imtiaz A. Khan' \\ 'Department of Microbiology, Immunology and Tropical Medicine, George Washington University, Washington, DC, USA. \\ 2Department of Immunology, MD Anderson Cancer Center, Houston, Texas, USA. \\ IInsect Infection and Immunity Lab, Department of Biological Sciences, George Washington University, Washington, DC, USA. \\ ${ }^{4}$ Immunology Laboratory, Vaccine Research Center, NIAID, NIH, Bethesda, Maryland, USA. \\ ${ }^{5}$ Laboratory of Immunovirology, Clinic Unit of Infectious Diseases, Microbiology and Preventive Medicine, \\ Institute of Biomedicine of Seville (IBiS), Virgen del Rocío University Hospital/CSIC/University of Seville, Seville, Spain. \\ 6Laboratorio InmunoBiología Molecular, Hospital General Universitario Gregorio Marañón, and Instituto de Investigación Sanitaria Gregorio Marañón, \\ Madrid, Spain. Networking Research Center on Bioengineering, Biomaterials and Nanomedicine (CIBER-BBN), Madrid, Spain.
}

\begin{abstract}
Advanced age is associated with immune system deficits that result in an increased susceptibility to infectious diseases; however, specific mediators of age-dependent immune dysfunction have not been fully elucidated. Here we demonstrated that aged mice exhibit poor effector $\mathrm{CD8}^{+} \mathrm{T}$ cell polyfunctionality, primarily due to $\mathrm{CD8}{ }^{+}$ T cell-extrinsic deficits, and that reduced $\mathrm{CD8}^{+} \mathrm{T}$ cell polyfunctionality correlates with increased susceptibility to pathogenic diseases. In aged animals challenged with the parasite Encephalitozoon cuniculi, effector CD8 ${ }^{+}$ T cell survival and polyfunctionality were suppressed by highly elevated TGF- $\beta 1$. Furthermore, TGF- $\beta$ depletion reduced effector $\mathrm{CD8}^{+} \mathrm{T}$ cell apoptosis in both young and aged mice and enhanced effector $\mathrm{CD8}^{+} \mathrm{T}$ cell polyfunctionality in aged mice. Surprisingly, intrinsic blockade of TGF- $\beta$ signaling in $\mathrm{CD8}^{+} \mathrm{T}$ cells was sufficient to rescue polyfunctionality in aged animals. Together, these data demonstrate that low levels of TGF- $\beta 1$ promote apoptosis of $\mathrm{CD8}^{+}$effector $\mathrm{T}$ cells and high TGF- $\beta 1$ levels associated with age result in both $\mathrm{CD8}^{+} \mathrm{T}$ cell apoptosis and an altered transcriptional profile, which correlates with loss of polyfunctionality. Furthermore, elevated TGF- $\beta$ levels are observed in the elderly human population and in aged Drosophila, suggesting that TGF- $\beta$ represents an evolutionarily conserved negative regulator of the immune response in aging organisms.
\end{abstract}

\section{Introduction}

Global demographic trends suggest that by the year 2050, 2 billion people will be over 60 years old (1). Age-associated immunological deficits, especially at the T cell level, are well described (2). While aged $\mathrm{CD}^{+} \mathrm{T}$ cell functionality has been extensively investigated and defects defined, the effect of aging on $\mathrm{CD} 8^{+} \mathrm{T}$ cells, a subset critical for protection against intracellular pathogens, remains to be studied in depth (3). Considering the imminent elderly population boom, combined with the fact that mechanistic underpinnings of poor $\mathrm{CD}^{+} \mathrm{T}$ cell response in aged individuals remains largely elusive, a thorough investigation of this subject is both timely and highly relevant.

Recent studies have demonstrated a critical role for $\mathrm{T}$ cell polyfunctionality (i.e., the capacity of a single cell to exhibit multiple effector functions, such as cytotoxicity and expression of various cytokines) in mediating a protective immune response $(4,5)$. The importance of this $\mathrm{T}$ cell subset is further emphasized by the observation that the improved protective response in HIVinfected nonprogressors does not correlate with the number of antigen-specific $T$ cells, but rather with the abundance of virusspecific polyfunctional $\mathrm{CD}^{+} \mathrm{T}$ cells (6). Furthermore, data from the early highly active antiretroviral therapy era suggests that the

Conflict of interest: The authors have declared that no conflict of interest exists. Citation for this article: J Clin Invest. 2014;124(6):2441-2455. doi:10.1172/JCI70522. degree and speed of immune recovery is reduced in older $\mathrm{HIV}^{+}$ patients (7). The effects of aging on $\mathrm{CD}^{+} \mathrm{T}$ cell polyfunctionality in HIV, as well as in other intracellular pathogens, has not been elucidated. In the present study, we addressed the progressive loss of $\mathrm{CD}^{+} \mathrm{T}$ cell polyfunctionality during aging using the obligate intracellular pathogen Encephalitozoon cuniculi, a member of the phylum Microsporidia.

Microsporidia cause self-limiting disease in immune-competent individuals; however, in HIV-infected patients and the elderly, it causes progressive infections (8-10). Symptoms in these high-risk groups can be severe and include chronic diarrhea, encephalitis, keratoconjunctivitis, and hepatitis $(8,9)$. Incidentally, current drug regimens against this pathogen are only partially effective (8). This is even more alarming in light of the high coprevalence of Microsporidia in AIDS patients (11), compounded with the fact that by the year 2015, more than $50 \%$ of the $\mathrm{HIV}^{+}$population in the United States will be older than 50 years (12). Considering that opportunistic infections are more prevalent in older $\mathrm{HIV}^{+}$patients (13), there is an urgent need to understand the mechanistic basis of susceptibility to Microsporidia in aging individuals. A previous study from our laboratory demonstrated that, similar to humans, aging mice exhibit elevated susceptibility to this infection that was coincident with progressive decline in the systemic response of $\mathrm{CD}^{+}$ $\mathrm{T}$ cells, a subset critical for protection against this pathogen (14). While in vitro studies suggested that dendritic cells were a mod- 
A Gated on splenic
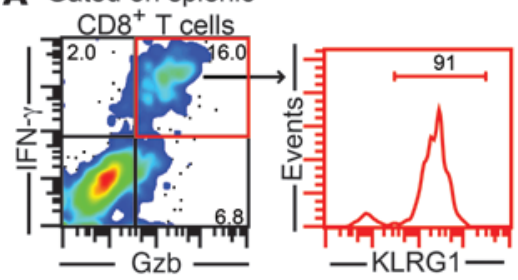

B Gated on splenic $\mathrm{CD} 8^{+} \mathrm{T}$ cells
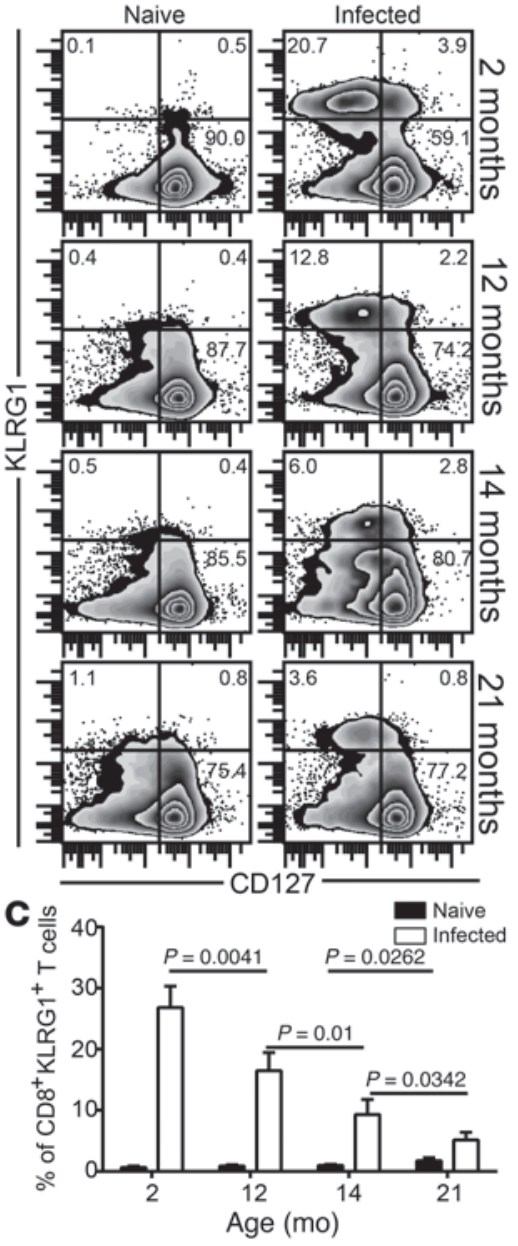

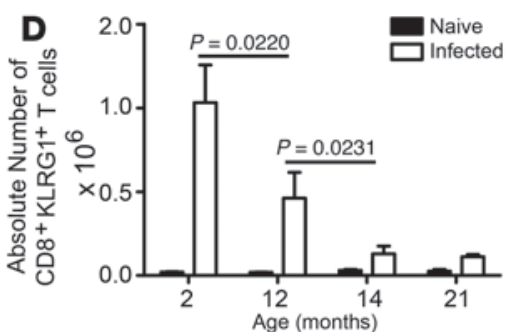

E Gated on splenic $\mathrm{CD}^{+} \mathrm{T}$ cells Young (2 months) Aged (14 months)
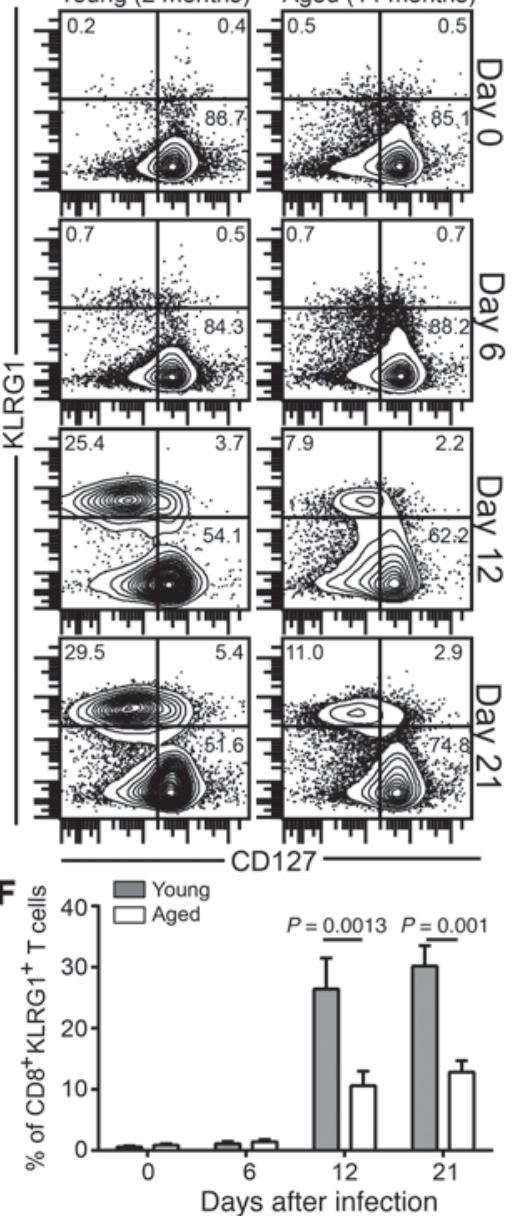

Figure 1

Attrition of effector CD8+KLRG1+ T cells in E. cuniculi-challenged aged mice. (A) Young mice were orally infected with E. cuniculi spores, and KLRG1 expression was assessed at day 12 after infection in IFN- $\gamma^{+}$Gzb ${ }^{+}$splenic CD8 ${ }^{+}$T cells. (B-D) Frequency (B and C) and absolute number (D) of CD8 ${ }^{+} \mathrm{KLRG} 1^{+} \mathrm{T}$ cells in E. cuniculi-challenged animals at 2, 12 , 14 , and 21 months of age. (E and F) KLRG1 ${ }^{+} \mathrm{CD} 8^{+}$kinetic was assessed in young and 14-month-old mice at days 0, 6, 12, and 21 after infection. Data represent 2 experiments with at least 4 mice per group. Numbers in dot plots and histograms denote percentages.

est contributor to this process, the mechanistic basis of poor $\mathrm{CD}^{+}$ $\mathrm{T}$ cell response in aged mice remains underexplored $(14,15)$.

Here, we found that during aging, the E. cuniculi-specific CD8 ${ }^{+}$ $\mathrm{T}$ cell polyfunctional response is preferentially lost in the effector $\mathrm{CD}^{+}{ }^{+} \mathrm{KLRG}^{+} \mathrm{T}$ cell subset, which constitutes the overwhelming majority of effector $\mathrm{CD}^{+} \mathrm{T}$ cells during acute infection. This attrition of polyfunctionality was primarily due to $\mathrm{CD}^{+} \mathrm{T}$ cell-extrinsic deficits in the hematopoietic compartment. Investigation of extrin- sic factors revealed highly elevated plasma TGF- $\beta 1$ levels in E. cuniculi-infected aged mice, despite the absence of Treg development. Depletion of TGF- $\beta 1$ in these animals not only restored the $\mathrm{CD} 8^{+}$effector response to levels seen in young animals, but also dramatically reduced pathogen burden. Further analysis demonstrated that blockade of $\mathrm{CD}^{+} \mathrm{T}$ cellintrinsic TGF- $\beta$ signaling in the aged hematopoietic environment was sufficient to partially restore $\mathrm{CD}^{+}$ $\mathrm{T}$ cell polyfunctionality. Interestingly, antibody treatment of young mice did not alter effector $\mathrm{CD}^{+}$ $\mathrm{T}$ cell polyfunctionality. Induction of high TGF- $\beta 1$ levels in these animals recapitulated the deficits noted in E. cuniculi-infected aged animals.

Our present findings demonstrate a novel role of TGF- $\beta 1$ : at low levels, it causes only apoptosis of effector $\mathrm{CD} 8^{+} \mathrm{KLRG}^{+} \mathrm{T}$ cells, but at high levels, it results in both apoptosis and loss of polyfunctionality. Furthermore, our observation of elevated TGF- $\beta$ homologs, concomitant with increased susceptibility to bacterial infection in an aging model of Drosophila, strongly suggests that TGF- $\beta 1$ may be an evolutionarily conserved negative regulator of immune response in aging organisms. More importantly, our data showing elevated TGF- $\beta 1$ in the elderly highlight the potential significance of our findings in clinically relevant settings.

\section{Results}

E. cuniculi-infected aged mice exhibit a sharply reduced polyfunctional response in the $C D 8^{+} K L R G 1^{+}$subset. $\mathrm{CD}^{+}$ $\mathrm{T}$ cell polyfunctionality is one of the hallmarks of robust protective immunity against intracellular pathogens. During the acute response against E. cuniculi infection, the majority of polyfunctional effector $\mathrm{CD}^{+} \mathrm{T}$ cells belonged to the KLRG1 ${ }^{+}$subset (Figure 1A). Hence, we sought to address whether the elevated susceptibility of aged mice to E. cuniculi was due to loss of this $\mathrm{CD}^{+} \mathrm{T}$ cell population. In agreement with our hypothesis, progressive ageing resulted in attrition of the $\mathrm{CD}^{+} \mathrm{KLRG} 1^{+}$subset in spleen, in terms of both frequency and absolute number (Figure 1, B-D). Independent of age, the overwhelming majority of $\mathrm{CD} 8{ }^{+} \mathrm{KLRG} 1^{+}$cells expressed low CD127 (also known as IL-7R $\alpha$ ), a well-established hallmark of short-lived effector T cells, which represent the bulk of the acute effector $\mathrm{CD}^{+} \mathrm{T}$ cell response against most infectious diseases (in contrast to memory precursor effector $T$ cells, i.e., $T$ cells destined to become memory $\mathrm{CD}^{+} \mathrm{T}$ cells) (16). The loss of effector $\mathrm{CD}^{+}{ }^{\mathrm{KLRG}} 1^{+} \mathrm{T}$ cells in E. cuniculiinfected aged animals was not due to delayed development of this subset (Figure 1, E and F). Further analysis revealed that while effector $\mathrm{CD} 8^{+} \mathrm{KLRG}^{-} \mathrm{T}$ cells exhibited unimpeded polyfunctional responses in E. cuniculi-infected mice up to 14 months of age, polyfunctional responses in terms of IFN- $\gamma$, TNF- $\alpha$, and granzyme B (Gzb) were sharply reduced in splenic effector CD ${ }^{+} \mathrm{KLRG} 1^{+}$ T cells in animals older than 12 months (Figure 2, A-D). Interestingly, regardless of host age or $\mathrm{CD}^{+}$subset, minimal IL-2 production was observed in this population. Similar trends in terms of 
A

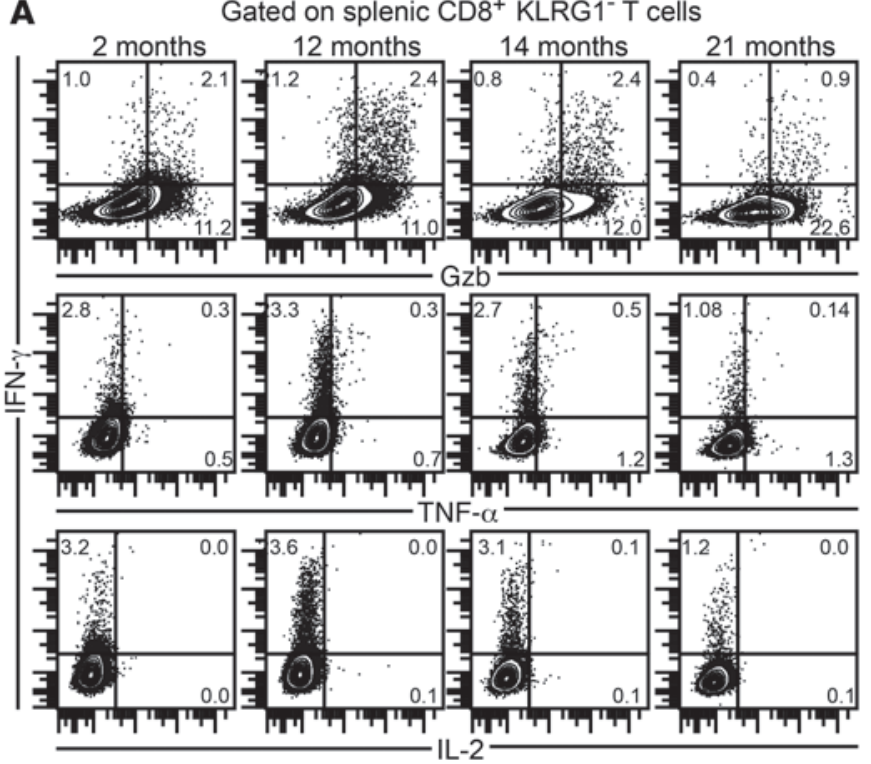

B

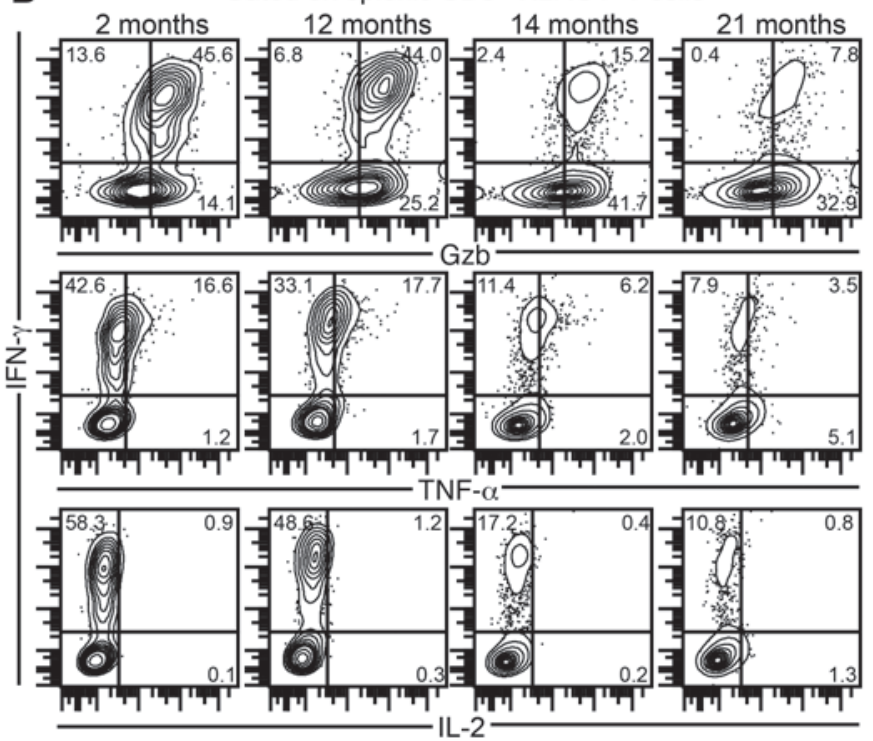

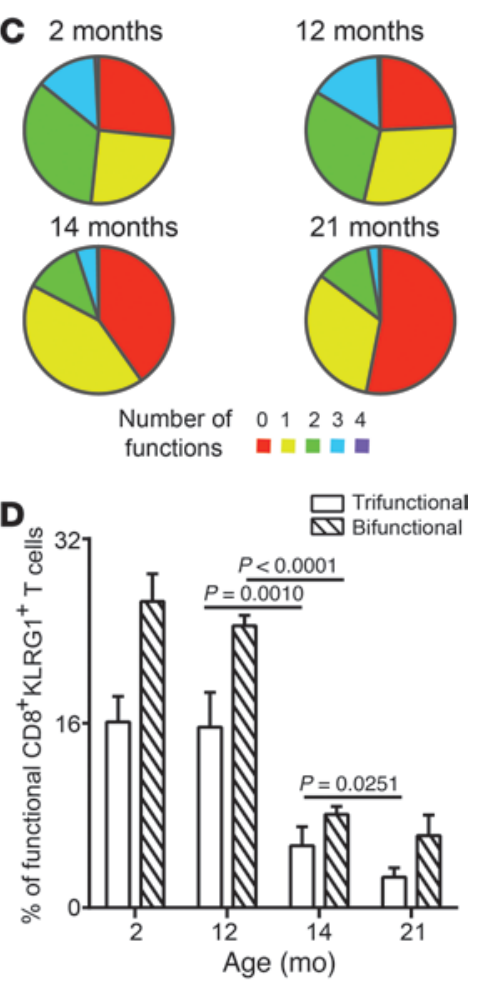

Figure 2

Downregulation of effector CD8+ T cell polyfunctionality in E. cuniculi-challenged aged mice. (A and B) KLRG1- (A) and KLRG1 ${ }^{+}$(B) effector $\mathrm{CD}^{+} \mathrm{T}$ cells from mice at various ages were assayed for IFN- $\gamma$, Gzb, TNF- $\alpha$, and IL-2 production at day 12 after infection. (C) Proportion of polyfunctional (IFN- $\gamma$, Gzb, TNF- $\alpha$, and/or IL-2) $\mathrm{KLRG} 1^{+} \mathrm{CD} 8{ }^{+} \mathrm{T}$ cells in these mice. (D) Percentage of KLRG1+CD8+ T cells exhibiting 2 or 3 functions (IFN- $\gamma$, Gzb, and/or TNF- $\alpha$ ), shown as bar graphs. Data represent 2 experiments with at least 4 mice per group. Numbers in dot plots denote percentage. poor $\mathrm{CD} 8^{+} \mathrm{KLRG}^{+}$response were noted in liver as well as in blood and brain (Supplemental Figure 1; supplemental material available online with this article; doi:10.1172/JCI70522DS1), which suggests that downregulated $\mathrm{CD}^{+} \mathrm{T}$ cell response in E. cuniculi-infected aged mice is not a phenomenon restricted to lymphoid tissue.

Poor development of effector $C D 8^{+} K L R G 1^{+} T$ cell polyfunctional response in aged mice is not $\mathrm{CD} 8^{+} \mathrm{T}$ cell-intrinsic. Since $\mathrm{CD} 8^{+} \mathrm{KLRG} 1^{+} \mathrm{CD} 8^{+}$polyfunctionality was specifically reduced in mice 14 months of age or older, we next sought to address whether this defect is $\mathrm{CD}^{+} \mathrm{T}$ cellintrinsic. To characterize this deficit, we challenged young $\mathrm{C} d 8^{-/}$ recipients adoptively transferred with $\mathrm{CD}^{+} \mathrm{T}$ cells from both naive young (CD90.1) and aged (CD90.2) donors $\left(1 \times 10^{7}\right.$ splenic cells from each pooled together, totaling $2 \times 10^{7}$ donor cells per recipient; Figure $3 \mathrm{~A}$ ). Analysis of splenic $\mathrm{CD}^{+}$response in the recipients revealed that cells from aged donors exhibited robust KLRG1 subset development and polyfunctional response, albeit modestly lower than those of young donors (Figure 3, B-F). Combined, these obser- vations suggest that the suboptimal effector $\mathrm{CD} 8{ }^{+} \mathrm{KLRG} 1^{+} \mathrm{T}$ cell response in aged mice is not caused primarily by $\mathrm{CD}^{+} \mathrm{T}$ cell-intrinsic deficits, but rather by $\mathrm{CD}^{+} \mathrm{T}$ cell-extrinsic defects.

We next assessed whether this $\mathrm{CD}^{+} \mathrm{T}$ cell-extrinsic defect was due to hematopoietic or nonhematopoietic factors, using a well-established mixed bone marrow chimera approach (17). T cell-depleted bone marrow from young (CD45.1) and aged (CD45.2) donors was injected at different ratios into lethally irradiated young (CD45.1) and old (CD45.2) recipients. Regardless of infection, bone marrow from aged donors was less efficient at reconstituting the hematopoietic compartment (Supplemental Figure 2). Similar to our observations in the adoptive transfer model, both young and aged donor $\mathrm{CD}^{+} \mathrm{T}$ cells in the respective chimeras elicited nearly similar $\mathrm{CD}^{+}{ }^{+} \mathrm{KLRG}^{+}$responses, which suggests that $\mathrm{CD} 8^{+} \mathrm{T}$ cell-intrinsic defects were not primarily responsible for the suboptimal effector response in aged mice. Likewise, the age of the nonhematopoietic compartment made only a modest effect on effector $\mathrm{CD}^{+} \mathrm{T}$ cell 
A
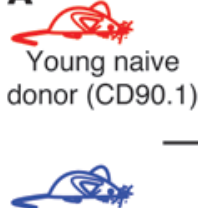

Aged naive donor (CD90.2) donor (CD90.1)

Magnetically purify

$\mathrm{CD}^{+} \mathrm{T}$ cells

(negative selection)

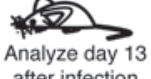

after infection

C

Gated on splenic ${ }^{+}$CD8 T cells (Naive recipients)

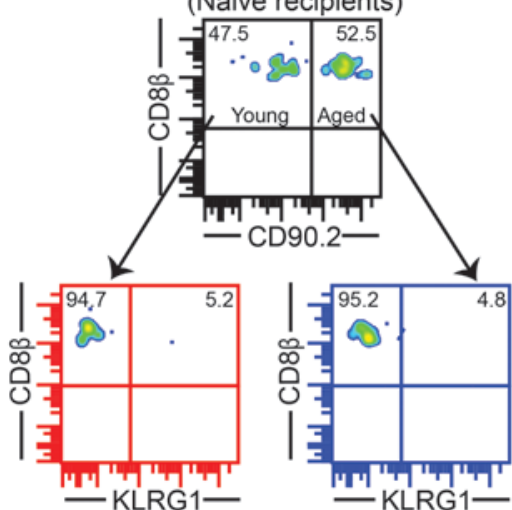

Gated on splenic $\mathrm{CD} 8^{+} \mathrm{T}$ cell subsets (Infected recipients)

E

KLRG1

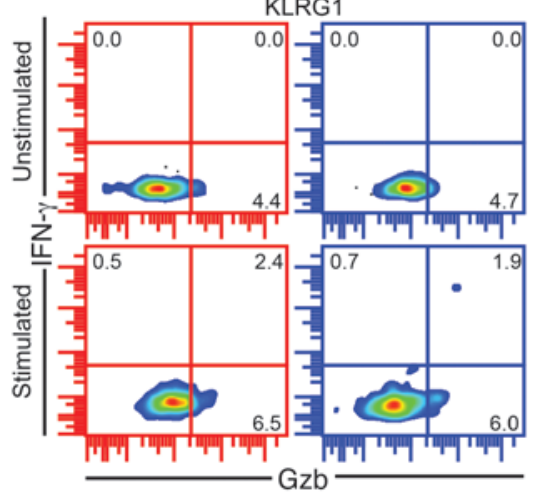

$\mathrm{KLRG}^{+}$

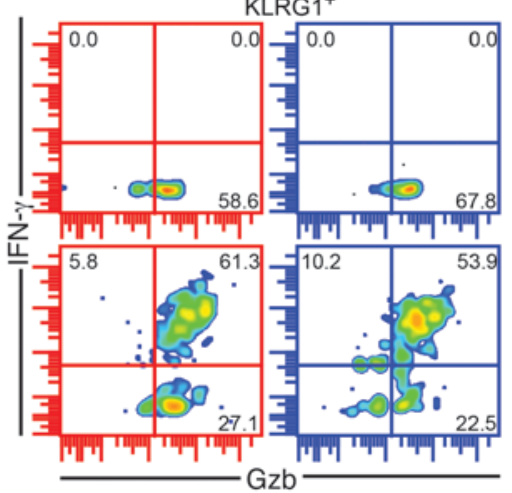

B

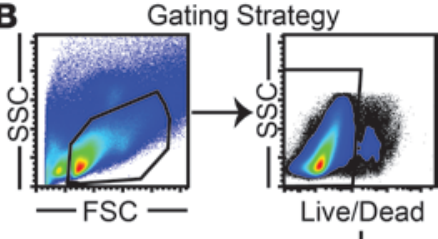
Young naive $\mathrm{Cd} 8^{-r}$

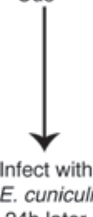

$24 \mathrm{~h}$ later

Gated on splenic $\mathrm{CD}^{+} \mathrm{T}$ cells (Infected recipients)
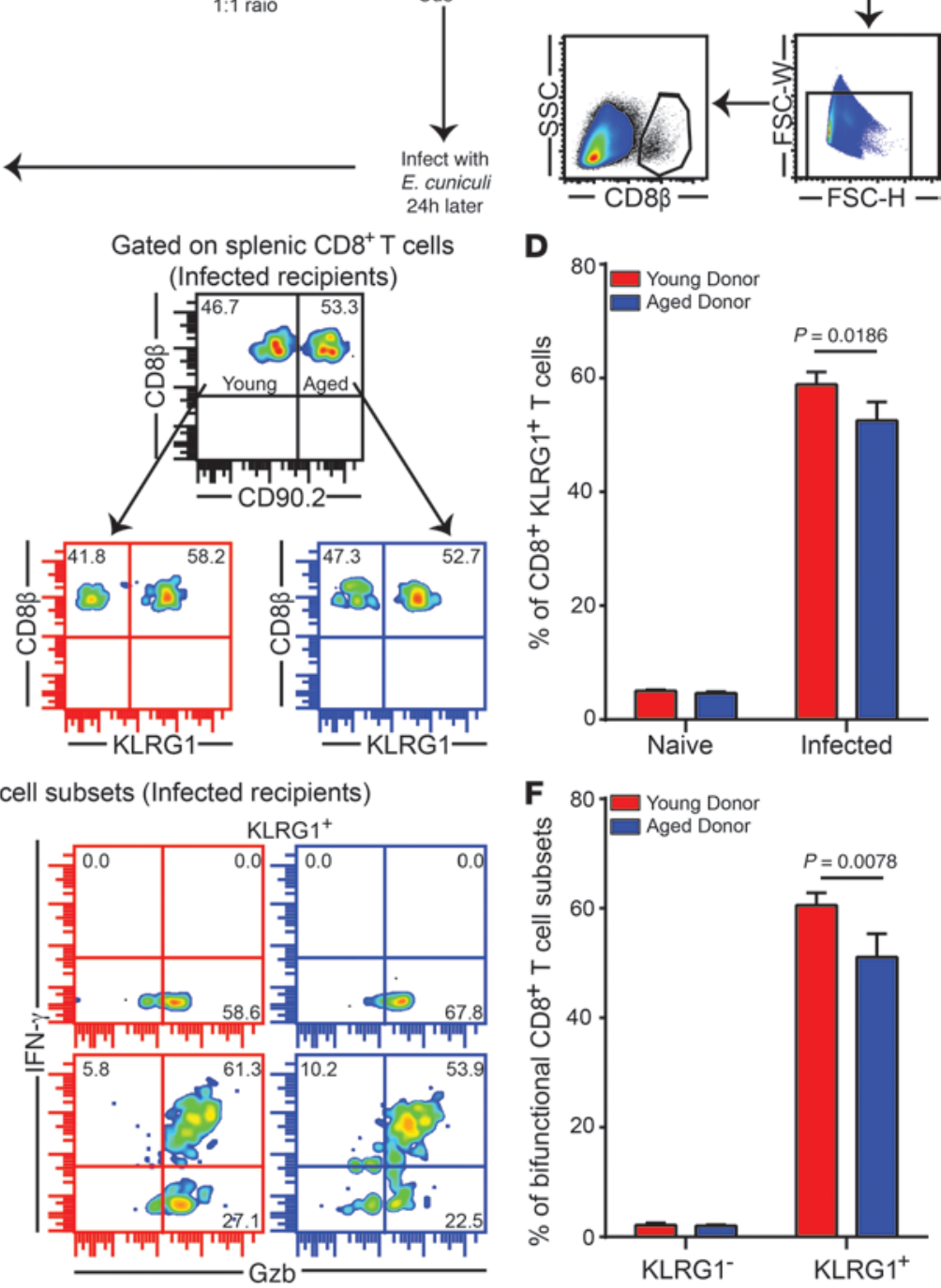

Figure 3

Poor effector $\mathrm{CD} 8^{+} \mathrm{KLRG} 1^{+} \mathrm{T}$ cell functionality is not primarily caused by CD8 ${ }^{+} \mathrm{T}$ cell-intrinsic deficits. (A) Equal number of CD8 ${ }^{+} \mathrm{T}$ cells from CD90.1 young (6-8 weeks old) and CD90.2 aged (14 months old) naive mice were adoptively transferred to young Cd8 $8^{-/-}$mice. 24 hours later, recipients were challenged with E. cuniculi, and CD8 $8^{+}$cell response was assessed after 12 days of infection. (B) Gating strategy. (C and D) Donor CD8 ${ }^{+} \mathrm{KLRG} 1^{+} \mathrm{T}$ cell frequencies in recipient mice. (E and F) IFN- $\gamma$ and Gzb production were evaluated in donor CD8 ${ }^{+} \mathrm{KLRG} 1^{+}$ and CD8 ${ }^{+} \mathrm{KLRG} 1^{-} \mathrm{T}$ cells in these animals. Data represent 2 experiments with 3-4 mice per group. Unless otherwise indicated, "aged" refers to 14- to 15-month-old mice throughout. Numbers in dot plots denote percentages.

response. However, chimeras with predominantly aged hematopoietic system produced sharply attenuated effector responses in terms of KLRG1 frequency and functionality (Supplemental Figure 2). Taken together, these observations suggest that the suboptimal effector $\mathrm{CD}^{+} \mathrm{T}$ cell response in aged mice is primarily the result of $\mathrm{CD}^{+} \mathrm{T}$ cell-extrinsic hematopoietic factors.

E. cuniculi infection of aged mice results in upregulation of plasma TGF$\beta 1$. Apart from TCR signaling and costimulatory milieu, cytokines produced by various cell types play a critical role in modulating the $\mathrm{CD}^{+} \mathrm{T}$ cell response (18). Since the poor effector $\mathrm{CD}^{+} \mathrm{T}$ cell response in aged mice was primarily due to $\mathrm{CD}^{+} \mathrm{T}$ cell-extrinsic hematopoietic deficits, we next assayed plasma cytokine levels in E. cuniculi-infected young and aged mice. TGF- $\beta 1$ was identified as a cytokine showing high levels of differential expression (Supplemental Figure 3 ). Plasma TGF- $\beta 1$ levels progressively increased with age in infected animals; however, regardless of age, no significant 
change in this cytokine was noted in naive mice, up to 28 months of age (Figure $4 \mathrm{~A}$ and data not shown). Since TGF- $\beta 1$ is produced by multiple cell types (19), we next sought to characterize whether elevated TGF- $\beta 1$ in aged mice was associated with a hematopoietic or nonhematopoietic system. Evaluation of plasma from the mixed bone marrow chimeras generated above revealed that chimeras with a predominantly aged hematopoietic system elicited the highest levels of TGF- $\beta 1$, whereas the aged nonhematopoietic system was at best a modest contributor (Figure 4B). Since Tregs are known to produce TGF- $\beta$, we assayed differential Treg development in aged mice (20). Interestingly, compared with the respective age-matched naive controls, upregulation of the Treg subset was not detected in E. cuniculi-challenged young or aged mice, in either lymphoid or nonlymphoid tissue. (Supplemental Figure 4). Moreover, no major difference in levels of IL-10, a hallmark cytokine of Tregs (20), was noted between $\mathrm{CD}^{+} \mathrm{T}$ cells in young and aged infected mice (Supplemental Figure 4). These data suggest that, regardless of host age, a robust Treg response does not occur in the E. cuniculi model. Nevertheless, to further verify whether Tregs or other T cell types were the primary contributors to plasma TGF- $\beta 1$ levels, young and aged mice were treated with anti-CD25 or anti-thymocyte antibody. Neither treatment significantly decreased plasma TGF- $\beta 1$ levels (Figure 4C). Taken together, these data suggest that while the hematopoietic system is primarily responsible for elevated TGF- $\beta 1$ in aged mice, $T$ cells are not the major producer of this cytokine. TGF- $\beta$ binding to its receptor, TGF- $\beta$ RII, activates its kinase domain and ultimately results in phosphorylation of SMAD2/3, a critical element of TGF- $\beta 1$ signal transduction (19). While TGF- $\beta$ RII levels were upregulated in aged mice on both CD8 ${ }^{+} \mathrm{KLRG}^{+}$and $\mathrm{CD} 8^{+} \mathrm{KLRG} 1^{-}$effector populations (Figure 4, D and E), only the former exhibited a sharp increase in levels of phosphorylated SMAD2/3 (Figure 4, F and G). To further verify that TGF- $\beta$ receptor upregulation in aged animals is $\mathrm{CD}^{+} \mathrm{T}$ cell-intrinsic, TGF- $\beta$ RII levels were assessed on KLRG1 ${ }^{+}$ effectors using the dual adoptive transfer and mixed bone marrow chimera approaches described above. TGF- $\beta$ RII upregulation on $\mathrm{KLRG}^{+}$effectors was not $\mathrm{CD}^{+} \mathrm{T}$ cell-intrinsic in nature, but rather $\mathrm{CD}^{+} \mathrm{T}$ cell-extrinsic and hematopoietic (Figure 4, H-J). Together, our data suggested that elevated TGF- $\beta 1$ levels and TGF- $\beta$ signaling on effector $\mathrm{CD}^{+} \mathrm{T}$ cells in aged mice is caused by $\mathrm{CD}^{+} \mathrm{T}$ cellextrinsic hematopoietic factors.

Anti-TGF- $\beta$ treatment revives polyfunctional effector $C D 8^{+} K L R G 1^{+}$ $T$ cell responses in aged mice. Since plasma TGF- $\beta 1$ level was elevated in aged animals and TGF- $\beta$ signaling was upregulated on $\mathrm{CD}^{+}$ $T$ cells in aged mice, we next evaluated whether TGF- $\beta$ depletion restored effector $\mathrm{CD}^{+} \mathrm{T}$ cell functionality in these animals. Young and aged animals were treated with anti-TGF- $\beta$ or isotype control antibody, and effector $\mathrm{CD}^{+} \mathrm{T}$ cell response was evaluated at day 12 after infection. Anti-TGF- $\beta$ treatment led to significantly increased frequency and absolute number of splenic effector $\mathrm{CD} 8^{+} \mathrm{KLRG} 1^{+} \mathrm{T}$ cells in both young and aged animals (Figure 5, A-C). To determine whether this increase was due to enhanced proliferation, Ki-67 levels in the effector $\mathrm{CD}^{+} \mathrm{T}$ cell population was assessed. Interestingly, while anti-TGF- $\beta$ treatment increased the frequency of cycling splenic effector $\mathrm{CD}^{+} \mathrm{T}$ cells in aged animals, no such effect was observed in young mice (Supplemental Figure 5). Apart from proliferation, differential apoptosis could also account for improved $\mathrm{KLRG}^{+}$effector development in anti-TGF- $\beta$-treated aged animals. Splenic effector $\mathrm{CD} 8^{+} \mathrm{KLRG}^{+} \mathrm{T}$ cells from aged animals were highly apoptotic, and anti-TGF- $\beta$ treatment reduced apoptosis in both young and aged animals (Supplemental Figure 5).
These data suggest that, in contrast to young mice, ameliorative effects of anti-TGF- $\beta$ treatment in aged animals are not restricted to apoptosis alone, but encompass both proliferation and apoptosis of effector $\mathrm{CD}^{+} \mathrm{T}$ cells. Further dissection of apoptotic factors in $\mathrm{KLRG} 1^{+}$effectors revealed that anti-TGF- $\beta$ administration reduced elevated levels of the proapoptotic molecule BIM in both young and aged mice (Supplemental Figure 5 and ref. 21). Since effector $\mathrm{CD}^{+} \mathrm{T}$ cell polyfunctionality is a hallmark of robust immune response (6), we next evaluated whether TGF- $\beta$ depletion revived $\mathrm{CD}^{+}$effector polyfunctionality in aged animals. Surprisingly, while anti-TGF- $\beta$ administration reinvigorated splenic effector $\mathrm{CD} 8^{+} \mathrm{KLRG} 1^{+} \mathrm{T}$ cell polyfunctionality in aged animals, it had no such effect in young mice (Figure 5, D-F). Additionally, regardless of age or antibody treatment, the functionality of effector $\mathrm{CD}^{+}{ }^{+} \mathrm{KLRG}^{-} \mathrm{T}$ cells remained unaltered (data not shown). Similar observations were also noted in liver (Supplemental Figure 6), a nonlymphoid tissue, which suggests that the ameliorative effect of anti-TGF- $\beta$ treatment is not tissue specific. Considering the significant effects of anti-TGF- $\beta$ treatment on KLRG $1^{+}$effector response, we hypothesized that this would alter the activation or maturation profile of this subset. However, apart from TGF- $\beta$ RII downregulation in antibody-treated aged mice, dramatic shifts in other markers were not noted (Supplemental Figure 7). Finally, we sought to address whether the augmented effector response was able to reduce susceptibility of aged mice to E. cuniculi. Anti-TGF- $\beta$ treatment reduced pathogen burden in aged mice to the level in young mice in both spleen and liver (Figure 5G). These data strongly support a model in which high TGF- $\beta$ level detrimentally affects effector $\mathrm{CD} 8{ }^{+} \mathrm{KLRG} 1^{+} \mathrm{T}$ cell polyfunctionality and compromises pathogen control.

$C D 8^{+} T$ cell-intrinsic TGF- $\beta$ signaling downregulates effector $C D 8^{+} K L R G 1^{+} T$ cell polyfunctionality in the aged microenvironment. The pleiotropic effects of TGF- $\beta$ on various immune cells and functions are dependent on the cellular and environmental context (22). Although the preceding experiments demonstrated that high levels of TGF- $\beta$ downregulated $\mathrm{CD}^{+} \mathrm{T}$ cell immunity in aged mice, they did not address whether TGF- $\beta$ affects $C D 8^{+} \mathrm{T}$ cells directly via TGF- $\beta$-TGF- $\beta$ RII interaction on these cells (i.e., $\mathrm{CD}^{+} \mathrm{T}$ cell-intrinsic TGF- $\beta$ signaling), indirectly via its action on antigen-presenting cells or other non-CD8 ${ }^{+}$cell types that subsequently downregulate the $\mathrm{CD}^{+} \mathrm{T}$ cell response (i.e., $\mathrm{CD}^{+} \mathrm{T}$ cellextrinsic TGF- $\beta$ signaling), or both. Therefore, we next examined whether $\mathrm{CD}^{+} \mathrm{T}$ cell-intrinsic TGF- $\beta$ signaling can regulate effector $\mathrm{CD}^{+} \mathrm{T}$ cell polyfunctionality in aged animals.

CD4-DNR mice have been widely used to study TGF- $\beta$ signaling in $T$ cells in vivo. These animals use the $C d 4$ promoter to express a dominant-negative form of human TGF- $\beta$ RII lacking the kinase domain in both $\mathrm{CD}^{+}$and $\mathrm{CD} 8^{+} \mathrm{T}$ cells that abrogates $\mathrm{T}$ cell TGF- $\beta$ signaling (23). However, CD4-DNR mice die within 6-8 months due to spontaneous development of inflammatory bowel disease. Moreover, $\mathrm{CD}^{+} \mathrm{T}$ cells from these animals cannot be transferred to WT hosts, as they are rejected (23). Since the defective polyfunctional $\mathrm{CD}^{+} \mathrm{T}$ cell response in aged mice was primarily $\mathrm{CD} 8^{+} \mathrm{T}$ cell-extrinsic and hematopoietic in nature, we used a mixed bone marrow chimera approach: young WT recipients were engrafted with bone marrow from young or aged WT donors and bone marrow from young CD4-DNR or WT animals in a 4:1 ratio (Figure 6A). Such a system allowed us to dissect $\mathrm{CD}^{+} \mathrm{T}$ cell-intrinsic and -extrinsic effects of TGF- $\beta$ signaling on effector $\mathrm{CD}^{+} \mathrm{T}$ cells without any of the caveats noted above (24). Evaluation of 

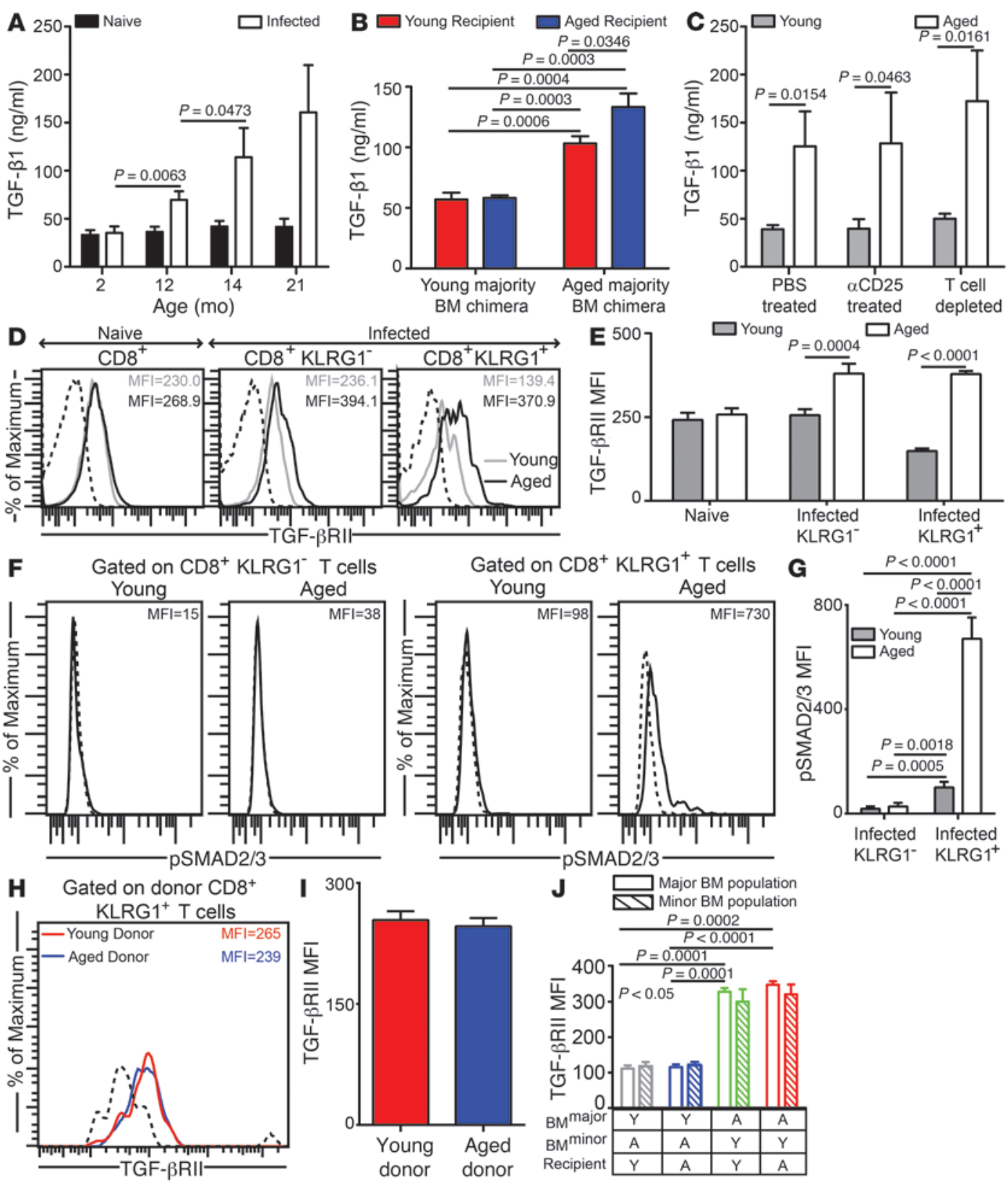

Figure 4

Plasma TGF- $\beta 1$ is highly elevated in E. cuniculi-challenged aged mice. (A) TGF- $\beta 1$ plasma levels in parasite-infected mice of various ages at day 12 after infection. (B) TGF- $\beta$ plasma levels in E. cuniculi-challenged young majority and aged majority BM chimeras generated in young or aged recipients. (C) Plasma collected from young (6-8 weeks old) or aged (14-15 months old) mice treated with PBS, with anti-CD25, or with antithymocyte to deplete T cells was assayed for TGF- $\beta$. (D and E) TGF- $\beta$ RII expression was measured on splenic CD8 ${ }^{+}$subsets in young (6-8 weeks old) and aged (14-15 months old) mice by polychromatic flow cytometry. (F and $\mathbf{G})$ Direct ex vivo SMAD2/3 phosphorylation on splenic CD8 ${ }^{+}$ subsets. (H and I) Young (CD90.1; 6-8 weeks old) and aged (CD90.2; 14 months old) CD8 ${ }^{+}$T cells from naive donors were adoptively transferred into young $\mathrm{Cd}^{-/-}$recipients, followed by parasite challenge. TGF- $\beta$ RII expression was evaluated in the recipients on donor effector CD8+KLRG $1^{+}$ T cells in spleen. (J) TGF- $\beta$ RII expression levels on splenic effector CD8+KLRG1 ${ }^{+} T$ cells in young majority or aged majority BM chimeras formed in young or aged recipients. Y, young; A, aged. Data represent 2 experiments with 4 mice per group. Numbers in histograms denote MFI.

effector KLRG1 frequency in these chimeras revealed that $\mathrm{CD}^{+} \mathrm{T}$ cell-intrinsic inhibition of TGF- $\beta$ signaling resulted in preferential expansion of mutant effector $\mathrm{CD} 8^{+} \mathrm{KLRG} 1^{+} \mathrm{T}$ cells in both Young WT:Young CD4-DNR and Aged WT:Young CD4-DNR chimeras, concomitant with downregulation of TGF- $\beta$ RII in the latter group
(Figure 6B and Supplemental Figure 8). These findings suggest that $\mathrm{CD}^{+} \mathrm{T}$ cell-intrinsic TGF- $\beta$ signaling downregulates effector $\mathrm{CD} 8{ }^{+} \mathrm{KLRG} 1^{+} \mathrm{T}$ cell development in both young and aged mice.

To further assess whether differential expansion of DNRbearing effector $\mathrm{CD}^{+} \mathrm{T}$ cells was due to increased proliferation, 
A

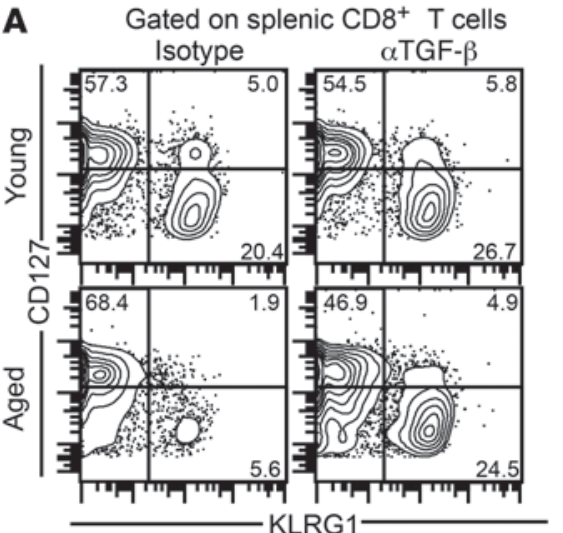

B

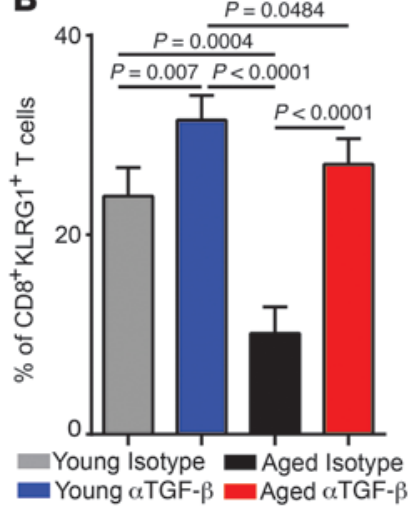

C
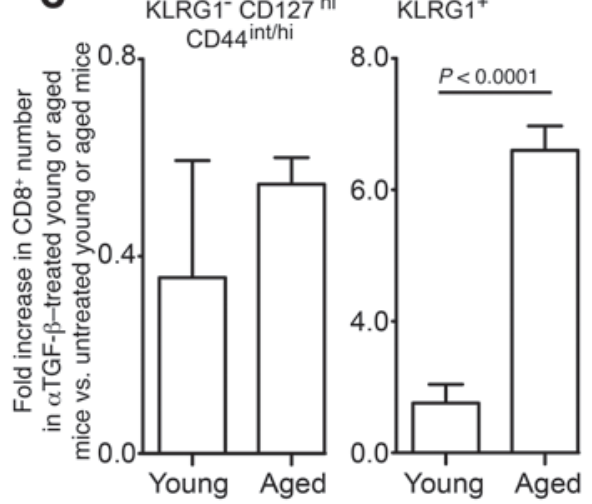

$\mathbf{F}$

D Gated on splenic $\mathrm{CD} 8^{+} \mathrm{KLRG}^{+} \mathrm{T}$ cells $\mathbf{E}$
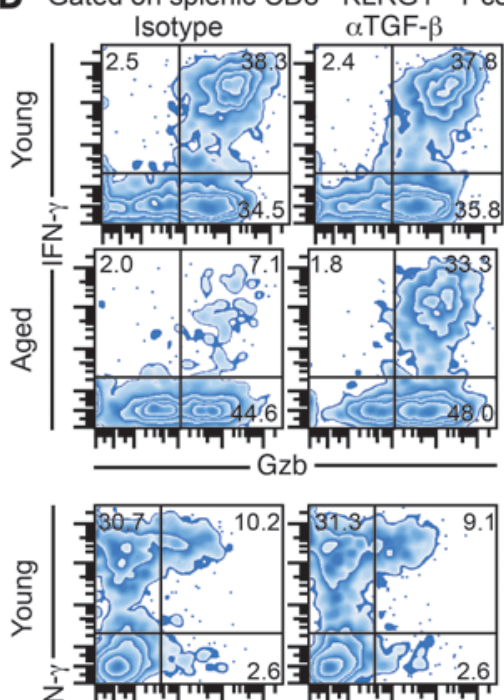

E Isotype
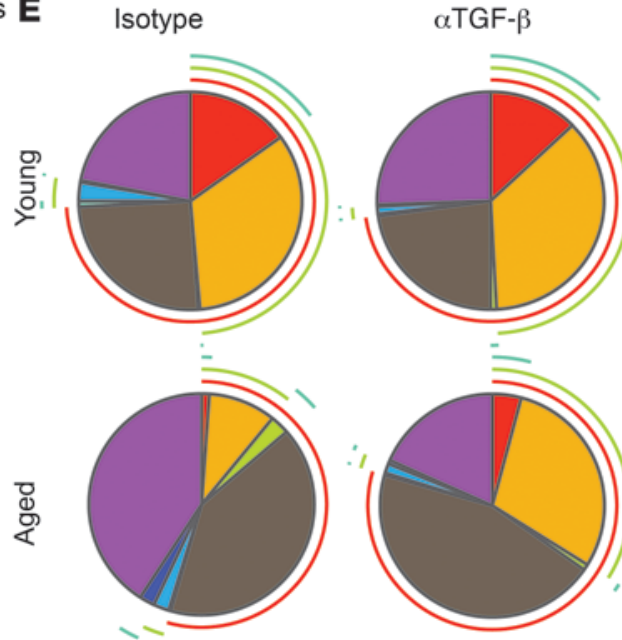

눈 융

Gzb
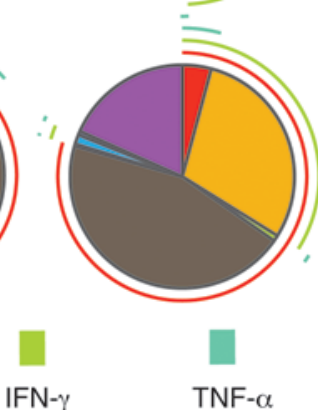

@ $141 \quad \begin{aligned} & P=0.0019 \\ & P<0.0001 \\ & P=0.0018\end{aligned}$

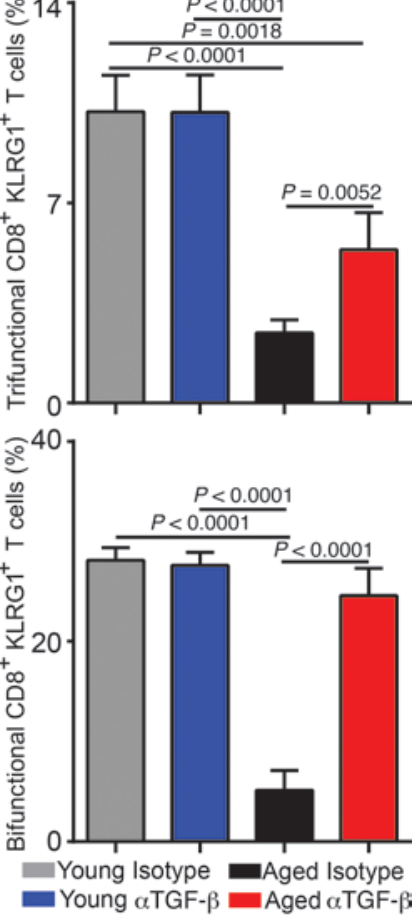

退
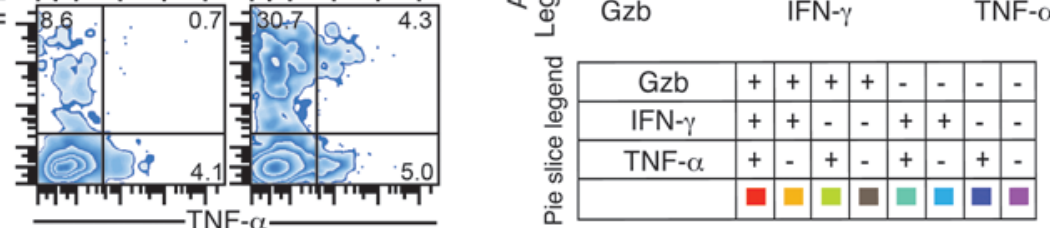

TNF- $\alpha$

G

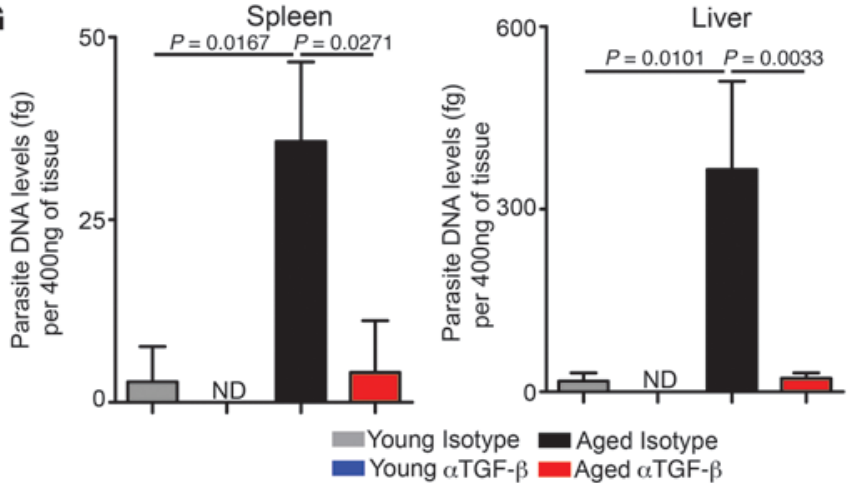

Figure 5

Anti-TGF- $\beta$ treatment rescues effector CD8+ $T$ cell polyfunctionality in E. cuniculi-infected aged mice. (A and B) KLRG1 expression on splenic $\mathrm{CD} 8^{+} \mathrm{T}$ cells was evaluated in young (6-8 weeks old) or aged (14-15 months old) mice treated with isotype control antibody or anti-TGF- $\beta$ at day 12 after infection. (C) Fold increase in absolute numbers of $\mathrm{CD}^{+} \mathrm{T}$ cell subsets in anti-TGF- $\beta$-treated young or aged mice compared with the respective isotype-treated controls. (D-F) IFN- $\gamma$, Gzb, and TNF- $\alpha$ production by effector CD8+KLRG1+ $T$ cells was evaluated by 6 -color flow cytometry. (G) Parasite DNA levels in spleen and liver was assessed in these mice by quantitative PCR. Data are representative of 3 experiments $(\mathbf{A}-\mathbf{F})$ or 2 independent experiments $(\mathbf{G})$ with 4-6 mice per group. Numbers in dot plots denote percentages. we performed intracellular staining for Ki-67. Whereas inhibition of TGF- $\beta$ signaling revived proliferation of mutant effector $\mathrm{CD}^{+}{ }^{+} \mathrm{KLRG}^{+} \mathrm{T}$ cells in Aged WT:Young CD4-DNR chimeras, no such effect was noted in Young WT:Young CD4-DNR chimeras (Supplemental Figure 8). Next, effector $\mathrm{CD}^{+} \mathrm{T}$ cells from the chi- meric animals were evaluated for apoptotic potential by examining BIM expression. Regardless of the age of the dominant hematopoietic compartment, mutant KLRG1 ${ }^{+}$effectors expressed lower levels of BIM than their WT counterparts (Supplemental Figure 8). Combined, these findings suggest that although differential pro- 
A

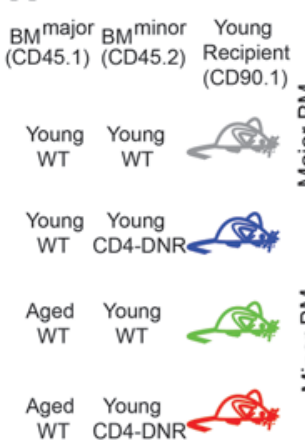

B

Gated on splenic $\mathrm{CD}^{+}{ }^{+} \mathrm{CD} 90.1^{-}$congenic $\mathrm{T}$ cells

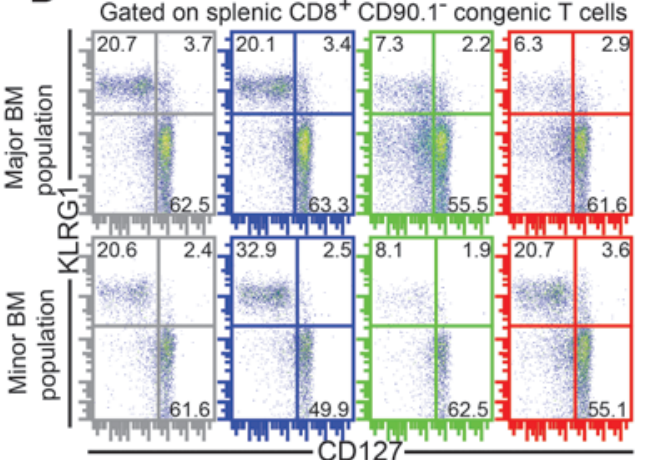

C

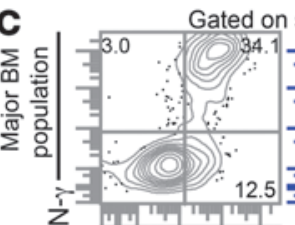

Gated on splenic CD8 ${ }^{+}$CD90.1 $1^{-} \mathrm{KLRG}^{+}$congenic T cells
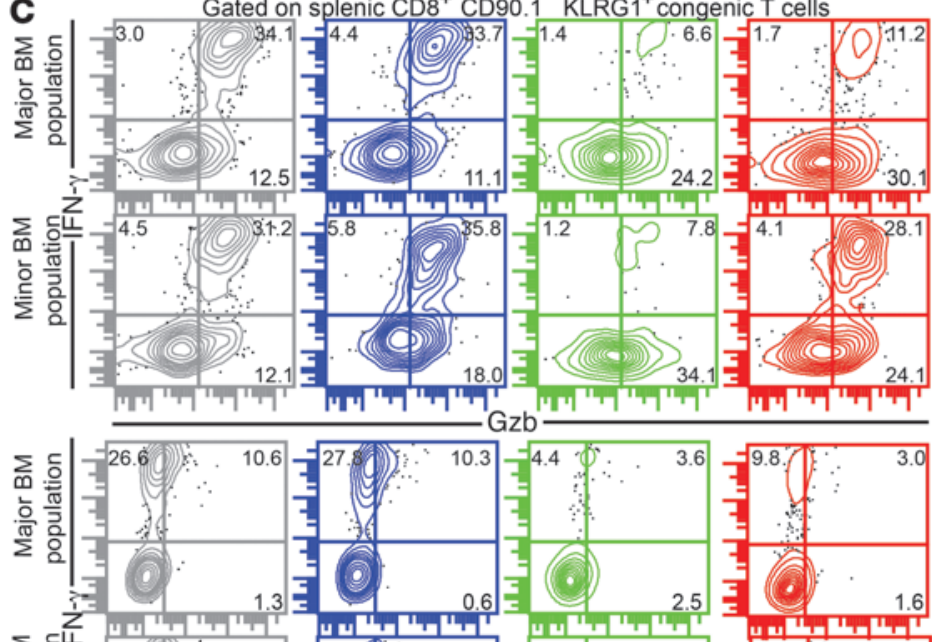

$\mathrm{Gzb}$
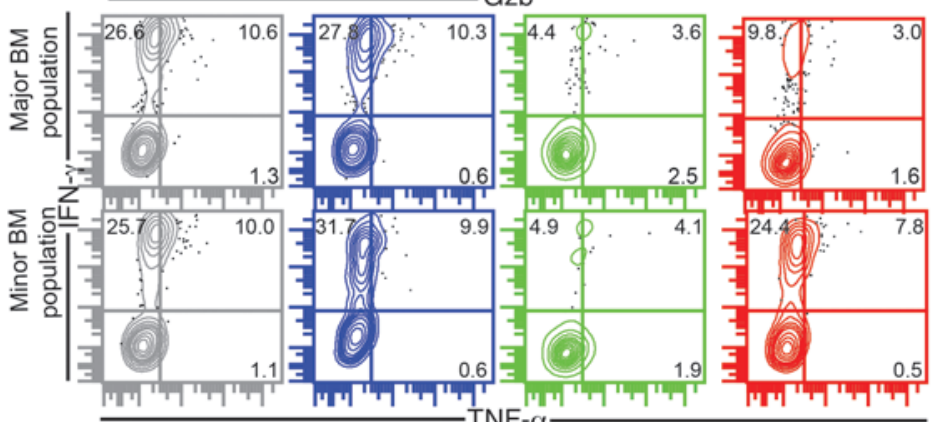

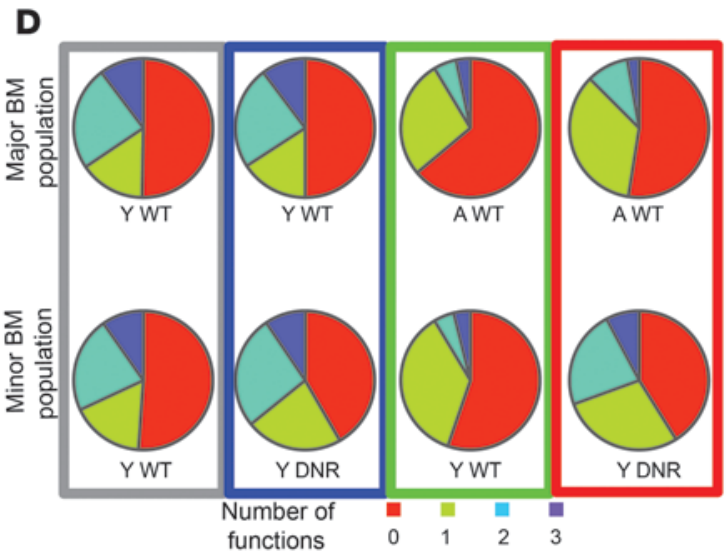

\section{E $\square$ Major BM population}
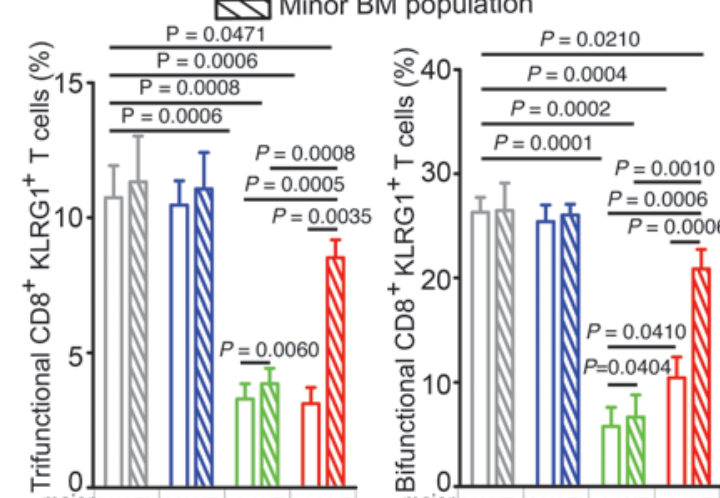

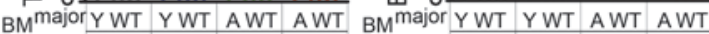

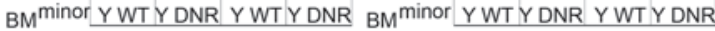

\section{Figure 6}

CD8 ${ }^{+}$T cell-intrinsic TGF- $\beta$ signaling results in poor development of E. cuniculi-specific effector CD8+ $T$ cell response in aged mice. (A) Mixed bone marrow chimera generation using a combination of young or aged WT and young CD4-DNR donors. (B) Percentage of splenic KLRG1+ CD8 ${ }^{+} T$ cells was evaluated in these chimeras at day 12 after infection. (C-E) Effector CD8 ${ }^{+}$T cell polyfunctionality (IFN- $\gamma$, Gzb, and/or TNF- $\alpha$ ) was assayed in chimeric mice by polychromatic flow cytometry. Data represent 2 experiments with 3-4 chimeras per group. Numbers in dot plots denote percentages.

liferation and apoptosis are the major mechanisms responsible for mutant effector $\mathrm{CD}^{+} \mathrm{T}$ cell expansion in the aged microenvironment, only reduced apoptosis is responsible for augmented effector CD4-DNR CD8 ${ }^{+} \mathrm{T}$ cell development in the young hematopoietic environment. Finally, we assessed whether TGF- $\beta$ signaling played a $\mathrm{CD}^{+} \mathrm{T}$ cell-intrinsic role on effector $\mathrm{CD} 8^{+} \mathrm{T}$ cell polyfunctionality in aged mice. Attenuation of TGF- $\beta$ signaling did not affect $\mathrm{CD}^{+} \mathrm{T}$ cell polyfunctionality in Young WT:Young CD4-DNR chimeras (Figure $6, \mathrm{C}-\mathrm{E})$. Interestingly, inhibition of TGF- $\beta$ signaling in chimeras engrafted primarily with an aged hematopoietic system rescued polyfunctionality of mutant effector $\mathrm{CD}^{+} \mathrm{T}$ cells, albeit partially. Additionally, WT effector $\mathrm{CD}^{+} \mathrm{T}$ cell bifunctionality, but not trifunctionality, was also modestly elevated in the Young WT:Young CD4-DNR group (Figure 6, C-E). Taken together, our data strongly suggest that $\mathrm{CD}^{+} \mathrm{T}$ cell-intrinsic (and, to a certain extent, $\mathrm{CD}^{+} \mathrm{T}$ cell-extrinsic) TGF- $\beta$ signaling plays a critical role in modulating effector $\mathrm{CD}^{+} \mathrm{T}$ cell polyfunctionality in E. cuniculi-infected aged mice.
Induction of high TGF- $\beta 1$ levels downregulates effector $C D 8^{+} T$ cell polyfunctionality in young mice. The data presented above strongly support a model whereby TGF- $\beta 1$ at low levels only causes effector $\mathrm{CD}^{+} \mathrm{T}$ cell apoptosis, whereas at high levels, it results in both apoptosis and loss of polyfunctionality. As mentioned above, the effects of TGF- $\beta 1$ are highly context dependent. Considering that deficits in the aging immune system are likely to be multifactorial, we specifically wanted to address whether induction of high TGF$\beta 1$ in young mice recapitulated the defects seen in aged animals. To address this, young Alb-TGF- $\beta 1$ mice were infected with $E$. cuniculi. These mice constitutively overexpress porcine TGF- $\beta 1$ in their liver (transgene present in $\mathrm{Y}$ chromosome), resulting in highly elevated plasma TGF- $\beta 1$ levels (25). Concomitant with elevated TGF- $\beta$ RII and BIM expression, KLRG $1^{+}$effector frequency was severely depressed in the transgenic animals compared with parental and littermate controls (Figure 7, A-F). Unlike aged mice, however, no deficit in effector $\mathrm{CD}^{+} \mathrm{T}$ cell proliferation was noted (Figure 7 , 
A Gated on splenic $\mathrm{CD}^{+} \mathrm{T}$ cells
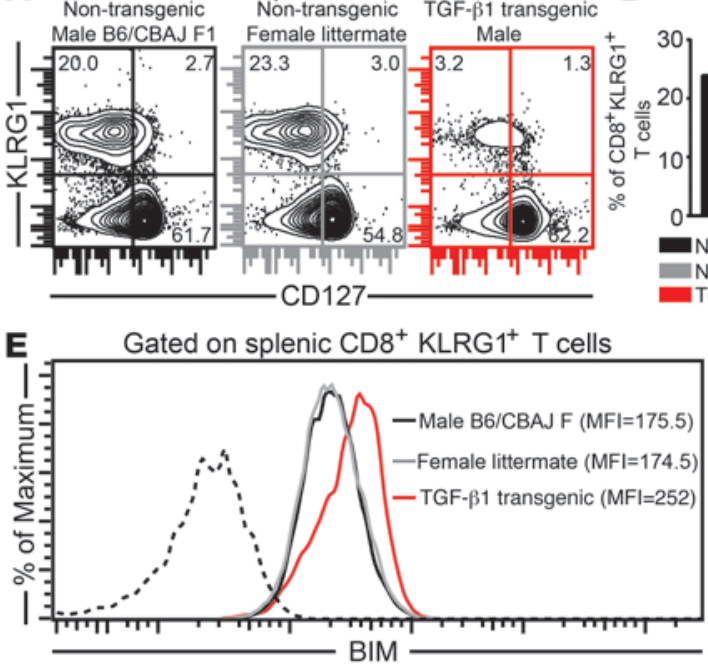

G

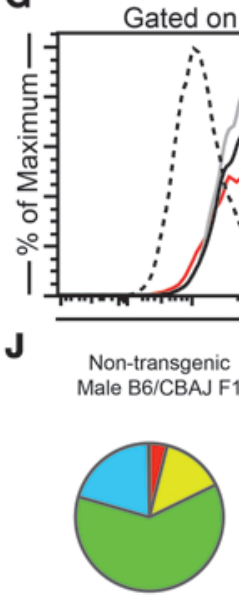

B

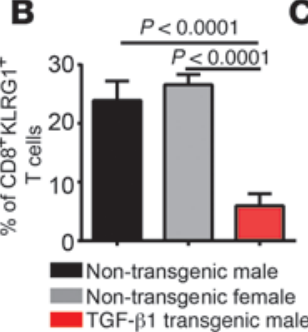

C

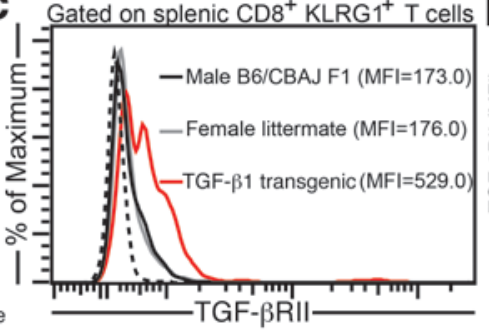

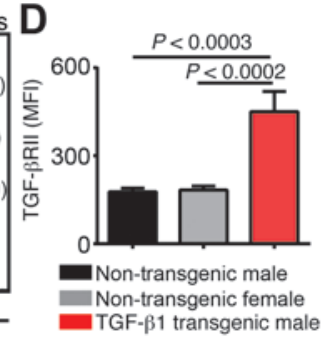

Gated on splenic $\mathrm{CD} 8^{+} \mathrm{KLRG}^{+}{ }^{+} \mathrm{T}$ cells

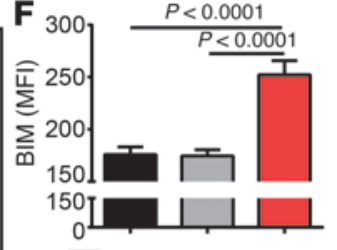

Non-transgenic male Non-transgenic female -TGF-ק1 transgenic male

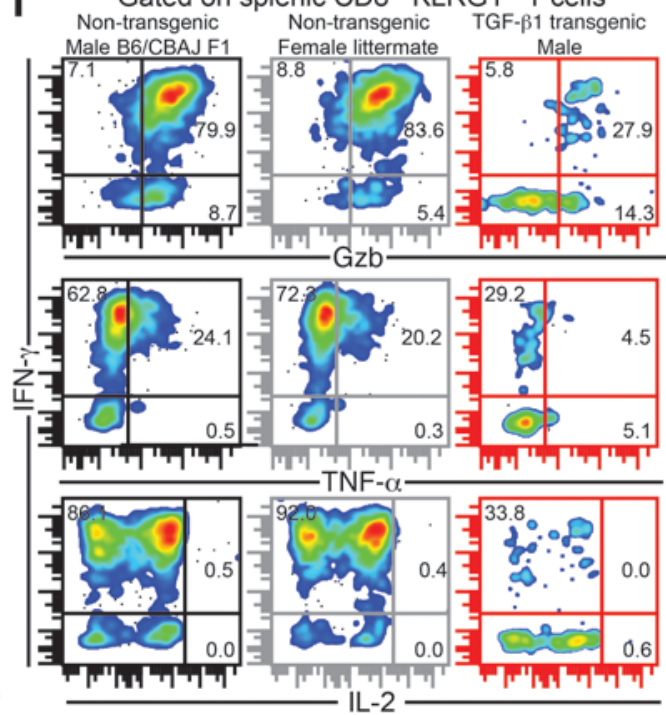

IL-2

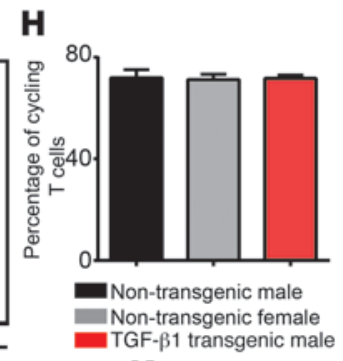
$\mathbf{K}$

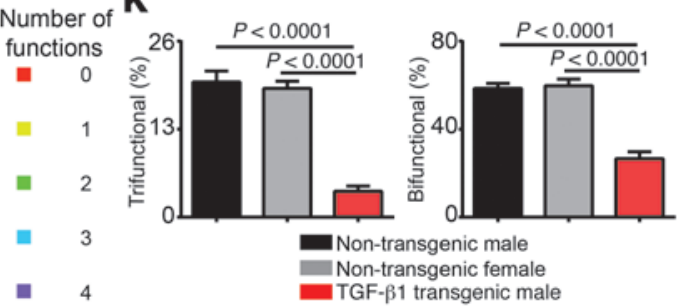

Figure 7

Elevated TGF- $\beta$ levels in young TGF- $\beta$ transgenic mice downregulates effector CD8 ${ }^{+}$T cell polyfunctionality. (A and B) KLRG1 expression was assessed on splenic CD8 ${ }^{+}$T cells in E. cuniculi-infected young Alb-TGF- $\beta 1$ mice and control groups (parental and littermate) at day 12 after infection. (C and D) TGF- $\beta$ RII expression on effector CD8 ${ }^{+}$KLRG1 ${ }^{+}$T cells, presented as histograms and bar graphs. (E and F) Intracellular BIM level in the KLRG1+ subset, assessed by flow cytometry. (G and $\mathbf{H}$ ) Frequency of proliferating effector CD8 ${ }^{+}$T cells. (I and $\left.\mathbf{J}\right)$ IFN- $\gamma$, Gzb, TNF- $\alpha$, and IL-2 production by effector CD8+KLRG1+ T cells, assayed by 7-color flow cytometry. (K) Percentage of KLRG1+ CD8 ${ }^{+} \mathrm{T}$ cells showing 2 or more functions (IFN- $\gamma, \mathrm{Gzb}$, and/or TNF- $\alpha$ ), shown as bar graphs. Data represent 3 independent experiments with 4 mice per group. Numbers in histograms denote $\mathrm{MFI}(\mathbf{C}$ and $\mathbf{E})$ or percentage $(\mathbf{G})$; numbers in dot plots denote percentages.

G and H). More importantly, akin to aged mice, elevated TGF$\beta 1$ dramatically reduced $C D 8^{+}$polyfunctionality in Alb-TGF- $\beta 1$ animals (Figure 7, I-K). To further confirm these observations, we used a more physiologically relevant murine model based on injections of murine TGF- $\beta 1$. Young C $57 \mathrm{BL} / 6$ mice were injected every third day i.v. with different doses of murine TGF- $\beta 1$. The concentration of the highest TGF- $\beta 1$ dose was extrapolated from plasma TGF- $\beta 1$ levels noted in aged mice. Consistent with our hypothesis, low-dose TGF- $\beta 1$ only caused attrition of effector $\mathrm{CD} 8{ }^{+} \mathrm{KLRG} 1^{+} \mathrm{T}$ cell frequency, but no change in the polyfunctional response, whereas high-dose TGF- $\beta 1$ caused loss of both frequency and functionality of effector $\mathrm{CD} 8^{+} \mathrm{T}$ cells (Supplemental Figure 9). Similar to aged mice, this TGF- $\beta 1$-dependent attrition of $\mathrm{CD}^{+}$polyfunctionality was found to be $\mathrm{CD} 8^{+} \mathrm{T}$ cell-intrinsic under high-dose TGF- $\beta 1$ conditions (data not shown). These data demonstrate a novel role of TGF- $\beta 1$ : at low levels, its effects are restricted to only apoptosis of effector $\mathrm{CD} 8^{+} \mathrm{KLRG} 1^{+} \mathrm{T}$ cells, but at high levels, it results in both apoptosis and loss of their polyfunctional ability.

TGF- $\beta 1$-mediated loss of effector $C D 8^{+} T$ cell polyfunctionality occurs after effector imprinting. While our data clearly demonstrated that high TGF- $\beta 1$ causes attrition of effector $C D 8^{+} K L R G 1^{+} T$ cell function, it was unclear whether this loss of functionality was due to poor de novo development of polyfunctional cells, or whether it occurred as a consequence of rapid loss of functionality after effector $\mathrm{CD}^{+} \mathrm{T}$ cell commitment is made. To address this, we sorted 


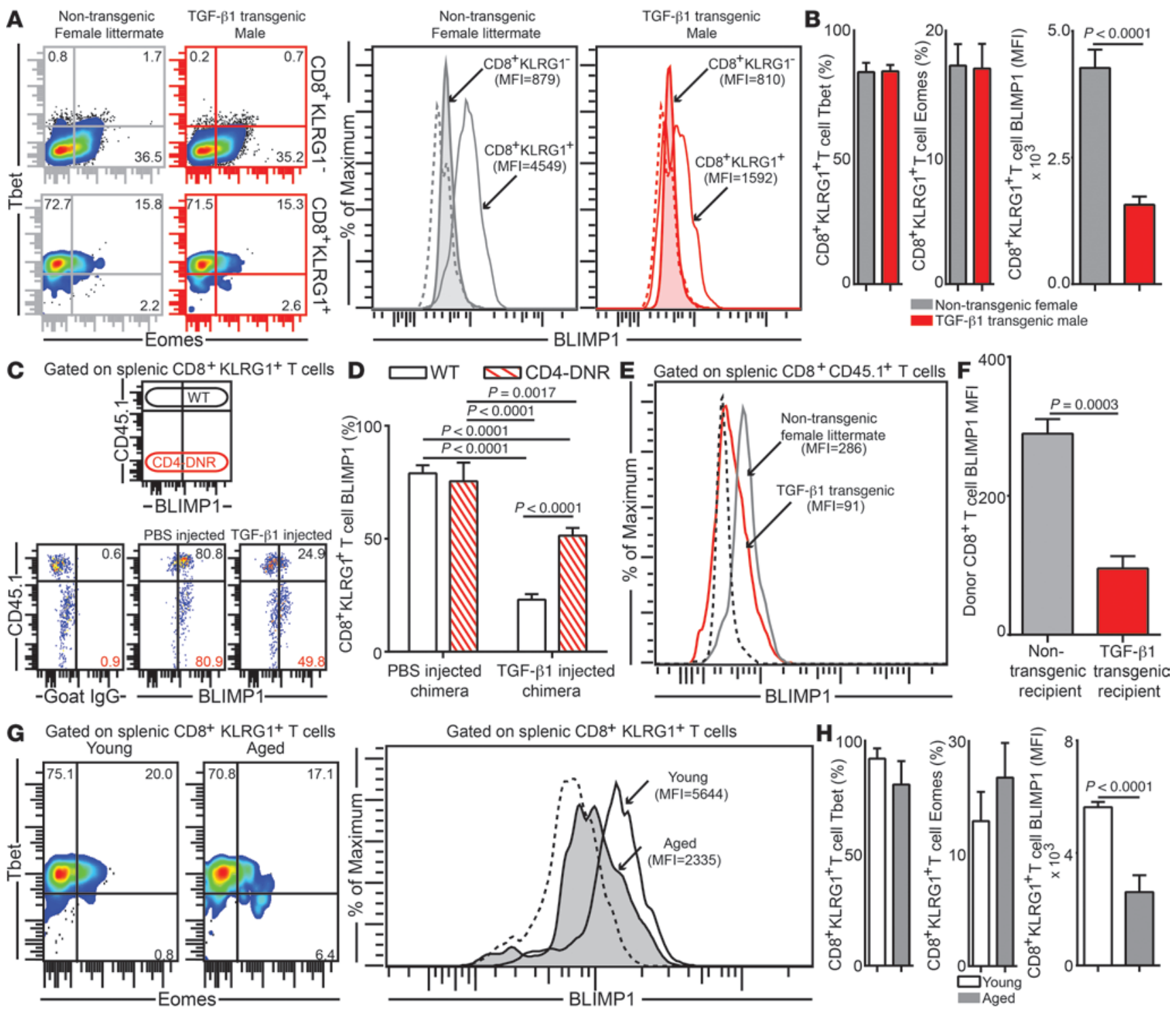

Figure 8

Highly elevated TGF- $\beta$ levels downregulate BLIMP1 expression on effector CD8+KLRG1+ $\mathrm{T}$ cells in the E. cuniculi model. (A and B) Expression levels of transcription factors Tbet, Eomes, and BLIMP1 in splenic CD8+KLRG1+ and CD8+KLRG1- T cells in young TGF- $\beta 1$ transgenic mice and littermate controls. (C and D) Acutely infected Young WT:Young CD4-DNR BM chimeras were treated i.v. with 500 ng murine TGF$\beta 1$ or PBS. BLIMP1 level was then evaluated in KLRG1+ effectors at day 12 after infection. (E and F) YFP+CD8 ${ }^{+}$effectors were sorted from E. cuniculi-challenged IFN- $\gamma$ reporter mice (CD45.1; day 12 after infection) and adoptively transferred to Alb-TGF- $\beta 1$ recipients or littermate controls at day 7 after infection. BLIMP1 expression in donor cells was assessed 5 days after transfer. (G and H) BLIMP1 level in KLRG1+ $\mathrm{CD}^{+} \mathrm{T}$ cells in young or aged mice at day 12 after infection. Data represent at least 2 experiments with $4-5$ mice per group. Numbers in dot plots represent percentages; numbers in histograms represent MFI.

CD8 ${ }^{+}$KLRG $1^{+}$CD $127^{\text {loyFPhi }}$ T cells from E. cuniculi-infected IFN- $\gamma$ reporter mice (CD45.1 Yeti mice) and transferred them to AlbTGF- $\beta 1$ mice and littermate controls at day 7 after infection. The overwhelming majority of the donor YFPhi cell also coexpressed Gzb (data not shown). Although evaluation of donor $\mathrm{CD}^{+} \mathrm{T}$ cells at day 5 after transfer revealed similar frequencies, the absolute number of donor cells in Alb-TGF- $\beta 1$ recipients was sharply reduced (Supplemental Figure 10 and data not shown). Concomitant with this, increased expression of TGF- $\beta$ RII and BIM was also noted in donor cells in TGF- $\beta$ transgenic animals (Supplemental
Figure 10). More importantly, donor cells in these mice exhibited a sharp decline in effector $\mathrm{CD}^{+} \mathrm{T}$ cell functionality. While these data do not fully refute the possibility of a suboptimal de novo development of polyfunctional effector cells, they clearly demonstrate that under high TGF- $\beta 1$ conditions, effector $\mathrm{CD}^{+} \mathrm{T}$ cell polyfunctionality is lost after cell imprinting.

High TGF- $\beta 1$ alters the transcriptional profile of effector $C D 8^{+} T$ cells. The downregulated polyfunctional effector $\mathrm{CD}^{+} \mathrm{T}$ cell response was only evident under conditions of high TGF- $\beta 1$, which suggests that elevated levels of this cytokine differentially turn on 
or off molecular switches that have a profound effect on $\mathrm{CD} 8^{+}$ $\mathrm{T}$ cell functionality. As transcription factors play a critical role in modulating effector $\mathrm{CD}^{+} \mathrm{T}$ cell function (26), we investigated whether these molecules were differentially regulated under high TGF- $\beta 1$ conditions. Levels of the T-box family transcription factors Tbet and eomesodermin (Eomes) were not significantly different in effector $C D 8^{+} \mathrm{KLRG}^{+} \mathrm{T}$ cells in parasite-infected TGF- $\beta$ transgenic mice or littermate controls (Figure 8, A and B). However, the expression of BLIMP1, a zinc finger transcription factor that plays an important role in effector $\mathrm{CD}^{+} \mathrm{T}$ cell functionality (27), was downregulated preferentially on KLRG $1^{+}$effectors in transgenic animals. To further assess whether reduced BLIMP1 expression was due to $\mathrm{CD}^{+} \mathrm{T}$ cell-intrinsic TGF- $\beta$ signaling, Young WT:Young CD4-DNR mixed bone marrow chimeras were injected with PBS or TGF- $\beta 1$. TGF- $\beta 1$-mediated BLIMP1 attenuation in effector $\mathrm{CD} 8^{+} \mathrm{KLRG}^{+} \mathrm{T}$ cells was dependent on both $\mathrm{CD} 8^{+}$ $\mathrm{T}$ cell-intrinsic and -extrinsic TGF- $\beta 1$ signaling (Figure $8, \mathrm{C}$ and D). Previous studies using conditional BLIMP1-deficient mice have demonstrated an inverse relation of the effector $\mathrm{CD}^{+} \mathrm{T}$ cellassociated transcription factor BLIMP1 and the memory $\mathrm{CD}^{+} \mathrm{T}$ cell-associated transcription factor Eomes $(27,28)$. However, in those studies, BLIMP1 was knocked out very early in the $\mathrm{CD}^{+} \mathrm{T}$ cell activation process.

Because BLIMP1 attenuation in E. cuniculi-infected TGF- $\beta$ transgenic mice did not result in a corresponding increase in Eomes in our model, we hypothesized that the TGF- $\beta 1$-mediated BLIMP1 decrease in $\mathrm{CD}^{+} \mathrm{T}$ cells occurred after effector lineage commitment. To address this, we utilized the IFN- $\gamma$ reporter adoptive transfer approach used earlier. In agreement with our hypothesis, high TGF- $\beta 1$ levels in Alb-TGF- $\beta 1$ recipients indeed downregulated BLIMP1 levels in donor $\mathrm{CD}^{+} \mathrm{T}$ cells after transfer (Figure 8, E and F). Finally, we sought to address whether effector $\mathrm{CD} 8{ }^{+} \mathrm{KLRG}^{+} \mathrm{T}$ cells in aged mice also reflect a skewed transcriptional profile. As expected, while only modest changes in Tbet and Eomes were noted in effector CD $8{ }^{+} \mathrm{KLRG} 1^{+} \mathrm{T}$ cells in aged mice, BLIMP1 expression in these cells was sharply reduced (Figure 8, $\mathrm{G}$ and $\mathrm{H})$. To the best of our knowledge, this is the first report describing the role of TGF- $\beta$ in modulating BLIMP1 expression. How differential BLIMP1 levels regulate effector $\mathrm{CD}^{+} \mathrm{T}$ cell functionality in aged animals is currently an important area of ongoing investigation in our laboratory.

TGF- $\beta$ homolog elevation also occurs in other models of aging. Finally, we addressed whether elevated TGF- $\beta 1$ was also noted in other models of aging. We infected young (1-week-old) and aged (5-week-old) Drosophila melanogaster adult flies with 2 Gramnegative bacteria, a nonpathogenic strain of E. coli and the insect pathogenic bacterium Photorhabdus luminescens (29), and the Gram-positive bacterium Micrococcus luteus. We examined the survival of the 2 groups of flies over time after microinjection with the bacteria. Aged flies were more susceptible to infection with E. coli and P. luminescens, but not with M. luteus, compared with young flies (Supplemental Figure 11A). The transcriptional activation of 2 TGF- $\beta$ superfamily members - dawdle (Daw), an activin/TGF- $\beta$-like signal, and glass bottom boat $(G b b)$, a bone morphogenetic protein-type signal (30) - were significantly upregulated in aged flies 12 hours after injection with either E. coli or P. luminescens, but not with $M$. luteus, compared with young flies (Supplemental Figure 11B). Together, these results suggest that increased TGF- $\beta$ signaling in infected aged organisms is an evolutionarily conserved homeostatic mechanism.
To determine the relationship between TGF- $\beta 1$ levels and age in humans, we studied plasma samples of 40 healthy donors ranging in age from 18 to 102 years (median, 66.4 years). All individuals were healthy subjects of mixed European descent from Seville, Spain, and $25 \%$ (10 of 40) were males. Individuals were categorized according to 3 different age groups: $<60$ years $(n=14), 60-80$ years $(n=17)$, and $\geq 81$ years $(n=9)$. Individuals younger than 60 showed statistically significant lower plasma levels of TGF- $\beta 1$ than the other age groups (Supplemental Figure 12A). In addition, TGF- $\beta 1$ levels were directly associated with age (Supplemental Figure 12B).

\section{Discussion}

The elevated susceptibility of aged individuals to pathogenic diseases is an underexplored area of research. The work presented herein demonstrates, for the first time, the mechanistic basis of attrition of effector $\mathrm{CD}^{+} \mathrm{T}$ cell polyfunctionality in the aging population. As mentioned above, development of robust effector $\mathrm{CD}^{+} \mathrm{T}$ cell polyfunctionality is a hallmark of potent immunity against intracellular pathogens. However, whether increased susceptibility to infectious diseases in the aging population is associated with declining polyfunctionality of these cells has never been addressed. Our present data demonstrated that in aged animals, effector $\mathrm{CD}^{+} \mathrm{T}$ cell polyfunctionality was preferentially lost in a TGF- $\beta$-dependent manner. More importantly, we discounted the conventional paradigm that effects of $\mathrm{CD}^{+} \mathrm{T}$ cell-intrinsic TGF- $\beta$ signaling are restricted to apoptosis alone $(24,31)$. We demonstrated that, under high-TGF- $\beta$ conditions such as aging, $\mathrm{CD}^{+}$ $T$ cell-intrinsic TGF- $\beta$ signaling exerted a detrimental effect on effector $\mathrm{CD}^{+} \mathrm{T}$ cell polyfunctionality. Given that elevated levels of TGF- $\beta$ homologs and increased susceptibility to Gram-negative pathogens were also noted in an aging Drosophila model, our results suggest that TGF- $\beta$ is probably a conserved negative regulator of immune response during aging. This notion was further confirmed by the elevated plasma TGF- $\beta 1$ levels observed in aged human subjects.

Interestingly, although we found that aged mice elicited a suboptimal effector $\mathrm{CD}^{+} \mathrm{T}$ cell polyfunctional response, the defect was not primarily $\mathrm{CD}^{+} \mathrm{T}$ cell-intrinsic in 14-month-old animals. Defects in effector $\mathrm{CD}^{+} \mathrm{T}$ cell response in aged mice of multiple infectious disease models have been attributed to diminished $\mathrm{T}$ cell repertoire $(3,32)$. However, our findings suggest that the poor $\mathrm{CD}^{+} \mathrm{T}$ cell response noted in aged mice was not exclusively caused by $\mathrm{CD} 8^{+} \mathrm{T}$ cell-intrinsic deficits, such as skewed $\mathrm{T}$ cell repertoire. Alterations in $T$ cell diversity primarily occur during the last third of the mammalian lifespan (>21 months for B6 mice) (33). Since deficits in effector $\mathrm{CD}^{+} \mathrm{T}$ cell polyfunctionality appear at a relatively early age in the E. cuniculi model, we restricted our analysis to 14-month-old mice, which may account for our divergent findings. It is also possible that E. cuniculi, being a eukaryote, has a potentially larger array of antigens, and as a result, cross-reactive $T$ cell clonotypes may make any $\mathrm{T}$ cell-intrinsic defects nonapparent during infection with this pathogen.

Using a mixed bone marrow chimera approach, we demonstrated that defective effector $\mathrm{CD}^{+} \mathrm{T}$ cell polyfunctionality in aged mice was essentially $\mathrm{CD}^{+} \mathrm{T}$ cell-extrinsic and hematopoietic in nature. One such extrinsic factor, TGF- $\beta 1$, was found to be progressively elevated in aged mice. However, the role of this cytokine on aged $\mathrm{CD}^{+} \mathrm{T}$ cells has never been addressed. A recent study using a Listeria model demonstrated that TGF- $\beta 1$ attenuates the $\mathrm{CD}^{+} \mathrm{T}$ cell response by mediating preferential apoptosis of effector $\mathrm{CD}^{+}$ 
$\mathrm{T}$ cells in young mice (31). However, in this study, no change in TGF- $\beta$-mediated proliferation or functionality of effector CD8 ${ }^{+}$ $\mathrm{T}$ cells was noted. Our findings in E. cuniculi-infected young mice treated with anti-TGF- $\beta$ antibody were in agreement with this report. In contrast, in E. cuniculi-challenged aged mice, which elicit much higher levels of TGF- $\beta$ than E. cuniculi- or Listeria-challenged young animals, antibody treatment not only decreased effector $\mathrm{CD}^{+} \mathrm{T}$ cell apoptosis, but also revived proliferation and functionality. This suggests that TGF- $\beta$ has divergent effects dependent on concentration in vivo. To further determine whether these conclusions were applicable to young mice, we investigated the role of TGF- $\beta$ in young TGF- $\beta$ transgenic mice as well as in TGF- $\beta$-injected young WT animals. In both cases, induction of high TGF- $\beta 1$ led to attrition of polyfunctionality and elevated apoptosis, akin to aged mice. In contrast to aging animals, high TGF- $\beta$ levels did not have any effect on $\mathrm{CD}^{+} \mathrm{T}$ cell proliferation in young TGF- $\beta$ transgenic mice. This divergent effect of TGF- $\beta$ on effector CD $8^{+}$ $\mathrm{T}$ cell cycling could be caused by differential signaling by cytokines such as IL-15, or by changes in other cytokine or costimulatory receptor milieu that may play an important role in $\mathrm{CD}^{+} \mathrm{T}$ cell expansion $(34,35)$.

In contrast to the E. cuniculi model, in which both $\mathrm{CD}^{+} \mathrm{T}$ cellintrinsic and -extrinsic TGF- $\beta$ signaling were involved in suppressing effector $\mathrm{CD}^{+} \mathrm{T}$ cell functionality, a study in a chronic viral model using Young WT:Young CD4-DNR chimeras demonstrated that TGF- $\beta$-mediated suppression of $\mathrm{CD}^{+} \mathrm{T}$ cell function is $\mathrm{CD}^{+} \mathrm{T}$ cellextrinsic (24). Unlike the chronic LCMV model mentioned above, $E$. cuniculi infection elicited high TGF- $\beta 1$ levels in aged animals that caused several-fold upregulation of TGF- $\beta$ signaling in these mice compared with their younger counterparts. Such high levels of differential TGF- $\beta$ signaling in aging models of E. cuniculi infection may explain the dependence on CD $8^{+}$T cell-intrinsic TGF- $\beta$ signaling for the modulation of effector $\mathrm{CD}^{+} \mathrm{T}$ cell polyfunctionality.

Our data raise an intriguing question: Why is the detrimental effect of elevated TGF- $\beta$ restricted to the effector $C D 8^{+}{ }^{+} L R G 1^{+}$ $\mathrm{T}$ cell subset? High expression of CD127 in concert with low KLRG1 expression is a hallmark of effector $\mathrm{CD}^{+} \mathrm{T}$ cells destined to become memory cells (16). Interestingly, elevated TGF- $\beta$ did not downregulate the functionality of this subset. Similar to our present observations, effector rather than memory $\mathrm{CD}^{+} \mathrm{T}$ cells were previously found to be more susceptible to TGF- $\beta$-mediated apoptosis in the Listeria model, despite higher expression of TGF$\beta$ RII in the latter subset (31). Based on our finding that SMAD2/3 phosphorylation was preferentially upregulated on KLRG1 ${ }^{+}$effectors, it is tempting to speculate that KLRG1- effectors may express higher levels of negative regulators of TGF- $\beta$ signaling, such as SMAD7. IL-7 signaling has been shown to augment SMAD7 activity in T cells (36), which in turn may make the KLRG1-CD127hi subset resistant to the downregulatory effects of TGF- $\beta 1$ (37). Alternatively, it is possible that due to the differential anatomical location of these 2 subsets in the tissue, KLRG1- effectors may localize in a microenvironment that is not conducive to TGF- $\beta$ signaling (38). Investigating these possibilities will be critical in order to better understand TGF- $\beta$ biology.

Our present findings also raise another fascinating question: Why do E. cuniculi-infected aged mice produce high TGF- $\beta$ levels? Since aging involves multifaceted defects, it can be argued that poor control of pathogens by a generally depressed immune system leads to elevated TGF- $\beta 1$ in these animals. However, the fact that we found no significant change in plasma TGF- $\beta 1$ levels in aged mice depleted of T cells, a subset critical for protection against E. cuniculi (39), argues against that possibility. This was further supported by our observations in the aging Drosophila model, in which infection with both an avirulent E. coli strain and the highly pathogenic bacterium $P$. luminescens elicited similar levels of TGF- $\beta$ homologs. Notably, TGF- $\beta$ superfamily members were recently shown to act as physiological regulators of the Drosophila immune response (40). Interestingly, our present data showed that even in aging models, high TGF- $\beta$ levels (or homologs) were only elicited during infection with E. cuniculi or Gram-negative bacteria, not with Gram-positive pathogens. Incidentally, the former group is known to be a potent inducer of TLR4 signaling $(41,42)$. Considering that TGF- $\beta$ can also act in an autocrine fashion (43) and that TLR4 is a potent inducer of TGF- $\beta$ signaling (44), it is tempting to speculate that differential TLR4 signaling may result in highly upregulated TGF- $\beta$ production in aging models of infection with these pathogens. Differential epigenetic regulation of the hematopoietic compartment is believed to be central to the decline of immune competence during aging (45). Whether a similar mechanism causes TLR4-dependent elevation of TGF- $\beta$ production by the aging hematopoietic system is an area of ongoing investigation in our laboratory.

As mentioned above, TGF- $\beta 1$ can be produced by multiple cell types, including Tregs (22). Additionally, TGF- $\beta$ has been shown to be important for Treg development (46). Paradoxically, in the E. cuniculi model, elevated TGF- $\beta 1$ levels in aged mice did not result in increased Treg development compared with naive controls. Considering that this pathogen elicits a poor IL- 2 response, it is possible that despite increased TGF- $\beta$ levels, suboptimal IL-2 signaling may impair the development of this $\mathrm{CD}^{+} \mathrm{T}$ cell subset (47). Although the aging hematopoietic system is the major source of TGF- $\beta 1$, T cells are not the primary producers of this cytokine. Since platelets are known to be an important reservoir of TGF- $\beta$ (48), ongoing experiments in our laboratory are attempting to address whether this population is the major contributor to elevated plasma TGF- $\beta$ level in parasite-challenged aged mice.

Another important question that we allude to in this study is the molecular mechanism involved in TGF- $\beta$-mediated attrition of effector $\mathrm{CD}^{+} \mathrm{T}$ cell polyfunctionality. Preliminary studies suggest that high TGF- $\beta 1$ levels downregulate expression of BLIMP1 after effector $\mathrm{CD}^{+} \mathrm{T}$ cell imprinting. Incidentally, BLIMP1 (at appropriate levels) has been shown to be important for effector $\mathrm{CD}^{+} \mathrm{T}$ cell functionality in viral models of infection $(27,49)$. Our demonstration of TGF- $\beta$-mediated decline in BLIMP1 levels in CD8 ${ }^{+}$ $T$ cells is novel, and the molecular basis of this downregulation remains unaddressed. It is currently unknown whether $\operatorname{Prdm} 1$, the gene encoding BLIMP1, is a direct SMAD target (50). However, based on previous studies demonstrating that TGF- $\beta 1$ inhibits the activity of NF- $\mathrm{KB}(51)$, a molecule that plays a direct role in modulating BLIMP1 expression (50), it will be critical to ascertain whether a similar mechanism suppresses $\mathrm{CD}^{+} \mathrm{T}$ cell polyfunctionality in aged mice. Considering that elevated TGF- $\beta 1$ during aging is not restricted to E. cuniculi alone, it will be important to decipher the pleiotropic role of this cytokine on various immune cells in other models of aging.

The proportion of individuals 60 or more years of age is projected to increase globally (52). Infectious diseases currently represent 1 of the 10 major causes of death in the elderly (53). Furthermore, by 2015 , more than $50 \%$ of the $\mathrm{HIV}^{+}$population in the United States will be older than 50 years (12). Hence, providing 
effective care for the aging population represents a major challenge for 21 st century medicine. One of the greatest impediments toward the development of improved therapeutic and prophylactic interventions in the elderly remains a poor understanding of the immune correlates of susceptibility to specific infectious diseases in the aging population. The critical role of anti-TGF- $\beta$ treatment in reinvigorating E. cuniculi-specific polyfunctional $\mathrm{CD}^{+} \mathrm{T}$ cell responses in aged mice, coupled with the observation that aged humans exhibited high levels of plasma TGF- $\beta$, provides insight into the initial rational basis for developing novel immunotherapeutic interventions, not only for the aging population, but also for coinfection scenarios, such as those involving helminths, in which high TGF- $\beta 1$ levels have been previously reported (54-56).

\section{Methods}

Mice. 6- to 8-week-old female C57BL/6 and B6-Ly5.2 (CD45.1) mice were purchased from the National Cancer Institute. For some experiments, female C57BL/6 mice were obtained from Harlan Laboratories. Similarly, aged female B6.PL-Thy $1^{\mathrm{a}} / \mathrm{CyJ}$ (CD90.1) mice, 6- to 8-week-old female $\mathrm{Cd} 8^{-1}$ mice, 5 -week-old female CD4-DNR mice, and 6- to 8-week-old female B6/ CBAJ F1 animals were purchased from the Jackson Laboratory. Alb-TGF$\beta 1$ and IFN- $\gamma$ reporter (Yeti) mouse colonies were maintained in house. Yeti mice were generated by the Locksley laboratory by targeted integration of an internal ribosome entry site linked to an EYFP coding sequence into the $3^{\prime}$ untranslated region of Ifng (57-59). This approach links the expression (translation) of IFN- $\gamma$ to YFP fluorescence. Aged mice $(\geq 12$ months) were directly purchased from Charles River. For some experiments, mice obtained from the above vendors were allowed to age further in house. Only data obtained from tumor-free mice were included in the experiments. Unless otherwise indicated, all $\mathrm{T}$ cell data were obtained from splenic tissue.

Cohort description. The cohort consisted of 40 free-living volunteers and nursing home residents from the Aljarafe health area of Seville, Spain. Only individuals with a self-sufficient health status were included. Exclusion criteria included a diagnosis of dementia, the presence of active infection within the 6 months preceding enrollment, hospital admission, or antitumor therapy or any treatment that could influence their immune status (mainly corticosteroids). These volunteers were part of the CARRERITAS cohort (60).

Human TGF- $\beta 1$ ELISA. TGF- $\beta$ levels were quantified in frozen plasmatic samples using Human TGF- $\beta 1$ Platinum ELISA (eBioscience) according to the manufacturer's instructions.

Parasites and infection. E. cuniculi parasites were maintained in vitro as previously described (41). For all experiments, mice were challenged with 1.5 $\times 10^{7}$ parasites via intragastric (i.g.) route. In vitro stimulation for cytokine detection was performed using irradiated parasites (2,200 Gy).

Bone marrow chimeras. Donor mice were treated with anti-thymocyte antibody every third day for 1 week. $T$ cell-depleted bone marrow was harvested using standard protocol, and $1 \times 10^{7}$ cells were injected i.v. into lethally irradiated (8 Gy per $20 \mathrm{~g}$ body weight) recipients (18). Young and aged donor animals were 5-6 weeks and 14 months of age, respectively; young and aged recipient animals were 6 weeks and 14 months of age, respectively. Chimerized mice were administered sulfamethoxazole and trimethoprim oral suspension (Hi-Tech Pharmacal) for the initial 5 weeks. 8 weeks after reconstitution, these animals were challenged with $E$. cuniculi.

In vivo antibody treatment and exogenous cytokine administration. For in vivo TGF- $\beta$ depletion, mouse anti-TGF- $\beta$ ( 2 mg; clone 1D11; BioXCell) or mouse IgG1 isotype-matched control antibody ( $2 \mathrm{mg}$; BioXCell) were injected i.p. every third day beginning 1 day prior to infection. For T cell depletion, rabbit polyclonal anti-thymocyte antibody $(100 \mu$ l; Inter-Cell
Technologies) was administered i.p. every third day beginning 1 day before parasite challenge. Following a previously established regimen, Tregs were depleted by injecting anti-CD25 (0.4 mg; clone PC61; BioXCell) antibody every third day starting at day 3 after infection (61). For TGF- $\beta$ injection in young mice, 100 or $500 \mathrm{ng}$ murine TGF- $\beta 1$ (Cell Signaling Technology) was injected i.v. every third day starting at day 7 after infection.

Mouse plasma ELISA and Luminex. Peripheral blood was collected by cardiac puncture and immediately centrifuged at $1,300 \mathrm{~g}$. Supernatant was collected in a new microcentrifuge tube and spun again at 5,200 $\mathrm{g}$ to remove residual red blood cells and platelets. Plasma samples were then stored at $-80^{\circ} \mathrm{C}$ for future use. For TGF- $\beta 1$ measurement, samples were acidified and then assayed for total TGF- $\beta 1$ using Mouse TGF- $\beta 1$ Platinum ELISA Kit (eBioscience). Other cytokine levels were computed according to standard protocols using commercial ELISA kits or via Luminex (University of Maryland Cytokine Core Facility).

Lymphocyte isolation, cell surface staining, and intracellular staining. Single-cell suspensions were prepared from spleen and liver using a standard protocol (62). Briefly, for spleen, single-cell suspensions were made by mechanical disruption followed by red blood cell lysis. For hepatic lymphocyte enrichment, livers were perfused with $10 \mathrm{ml}$ cold PBS, excised, minced, and passed through a meshed screen. Cells were washed in cold PBS, and 1 liver equivalent was suspended in $15 \mathrm{ml}$ of $30 \%$ Percoll (Sigma-Aldrich) solution in the presence of $100 \mathrm{IU} / \mathrm{ml}$ heparin (Sigma-Aldrich). The suspension was centrifuged for 10 minutes at $930 \mathrm{~g}$, and the pellet was resuspended in cold PBS with $2 \%$ FCS. Antibodies against the following molecules were used in cell surface staining and intracellular staining of lymphocytes: $\mathrm{CD} 8 \beta$ (clone H35-17.2; eBioscience), CD4 (clone GK1.5; eBioscience), CD3 (clone 17A2; eBioscience), Tbet (clone 4B10; Santa Cruz Biotechnology), Eomes (clone Dan11mag; eBioscience), BLIMP1 (polyclonal [N20]; Santa Cruz Biotechnology), FoxP3 (clone FJK-16s; eBioscience), CD90.1 (clone OX-7; BioLegend), CD45.1 (clone A20; BioLegend), IFN- $\gamma$ (clone XMG1.2; BD Biosciences), Gzb (clone GB11; Invitrogen), TNF- $\alpha$ (clone MP6-XT22; eBioscience), IL-2 (clone JES6-5H4; eBioscience), IL-10 (clone JES5-16E3; eBioscience), Ki-67 (clone B56; BD Biosciences), active caspase-3 (clone C92-605; BD Biosciences), BIM (polyclonal; Cell Signaling Technology), KLRG1 (clone 2F1; eBioscience), TGF- $\beta$ RII (polyclonal; R\&D Systems), CD44 (clone IM7; BioLegend), CD62L (clone MEL-14; eBioscience), CD27 (clone LG.3A10; BioLegend), CD127 (clone A7R34; eBioscience), CD122 (clone TM- $\beta 1$; BioLegend), CXCR3 (clone CXCR3-173; BioLegend), CD25 (clone PC61; eBioscience).

Unless otherwise indicated, intracellular staining was performed after surface staining, using Cytofix/Cytoperm Kit (BD Biosciences) per the manufacturer's protocol. For detection of transcription factors, instead of Cytofix/Cytoperm Kit, FoxP3 Fixation/Permeabilization Kit (eBioscience) was used. In all cases, Live/Dead Aqua or Live/Dead Near-IR (Invitrogen) staining was performed prior to surface staining.

Cell fluorescence was measured with a BD FACS Calibur or a BD FACS Aria cytometer or with a Cytek upgraded 8-color BD FACS Calibur cytometer that accounts for differences in fluorescence scale. Data were analyzed using FlowJo (TreeStar) software. For data acquired using digital cytometers, singlet population was analyzed. Gating for positive and negative populations was set up based on fluorescence-minus-one (FMO) controls.

Staining for SMAD2 $/ 3$ phosphorylation was performed using a modified protocol. Spleens were collected in PBS with $0.5 \%$ paraformaldehyde, and single-cell suspensions were generated by mechanical disruption. $2 \times 10^{6}$ cells/well were plated in a 96-well U-bottomed plate and incubated at $37^{\circ} \mathrm{C}$ for 15 minutes. Next, cells were washed twice in PBS and permeabilized in $90 \%$ methanol at $-20^{\circ} \mathrm{C}$ for 15 minutes. Cells were then washed twice in PBS and blocked for 15 minutes in PBS with $0.5 \%$ BSA at room temperature. Cells were stained with antibody against phospho-SMAD2/3 (Ser423/425) (polyclonal; Santa Cruz Biotechnology; 1:50 dilution) and other relevant 
surface markers for 30 minutes at room temperature. Subsequently, cells were washed twice in PBS and then stained with FITC-conjugated anti-goat antibody for 30 minutes at room temperature. Samples were washed twice, and data were acquired using the aforementioned cytometers.

For cytokine detection, restimulation was carried out for 16 hours with irradiated E. cuniculi and host cells at a 1:1 ratio in supplemented Iscove complete DMEM at $37^{\circ} \mathrm{C}$ in $5 \% \mathrm{CO}_{2}$. Monensin $(0.65 \mu \mathrm{l} / \mathrm{ml}$; BD Biosciences) and brefeldin A (0.65 $\mu \mathrm{l} / \mathrm{ml}$; BD Biosciences) were added during the final 9 hours of stimulation. Transcription factors were similarly detected after stimulation without adding any brefeldin A or monensin. For restimulation of hepatic lymphocytes, $5 \times 10^{5}$ splenocytes from naive $C d 8^{--}$mice were mixed with equal numbers of hepatic lymphocytes from infected mice, and restimulation was similarly carried out. After data analysis using FlowJo (TreeStar), computation of T cell polyfunctionality was performed using PESTLE and SPICE programs (provided by M. Roederer, NIH, Bethesda, Maryland, USA).

For some adoptive transfer experiments, $\mathrm{CD}^{+} \mathrm{T}$ cells were first positively selected using anti-biotin-coated microbeads (Miltenyi Biotec), followed by labeling with subset-specific antibodies and sorting using a BD FACS Aria cytometer. In other adoptive transfer experiments, bulk CD8 ${ }^{+} \mathrm{T}$ cells were negatively selected using a combination of anti-CD4 (clone GK1.5; eBioscience), CD11b (clone M1/70; eBioscience), anti-CD11c (clone N418; eBioscience), anti-B220 (clone RA3-6B2; eBioscience), anti-CD49b (clone DX5; eBioscience), and anti-Ter119 (clone TER-119; eBioscience) biotinylated antibodies and biotin-coated microbeads (Miltenyi Biotec).

Quantification of parasite burden by real-time PCR. Animals were euthanized via $\mathrm{CO}_{2}$ overdose, and tissue (spleen and liver) was harvested and flash frozen in liquid nitrogen. DNA was extracted from entire organs using a Qiagen DNeasy Tissue Kit (Qiagen). Amplification of parasite DNA from 400 ng purified tissue DNA was performed using primers (specific for a 268-bp DNA sequence of the SSU rRNA gene from E. cuniculi) at $10 \mathrm{pMol}$ each per reaction (IDT) and amplified by real-time fluorogenic PCR using iQ SYBR Green Supermix (Biorad) on an iCycler iQ thermal cycler (BioRad) (63). The following conditions were used: 3 minutes at $95^{\circ} \mathrm{C}$; 40 cycles of $45 \mathrm{sec}-$ onds at $95^{\circ} \mathrm{C} ; 60$ seconds at $60^{\circ} \mathrm{C}$; and 45 seconds at $72^{\circ} \mathrm{C}$. Parasite DNA equivalents were used as a standard curve against which infected mouse tissue DNA Ct values were compared. Parasite genome equivalents were calculated via extrapolation from the standard curve.

Drosophila experiments. 1- and 5-week-old Drosophila melanogaster adult flies (Oregon R strain) were used in all experiments. Flies were reared under standard conditions as previously described (64). E. coli (ATCC no. 25254) and P. luminescens subsp. laumondii (strain TT01) were grown in Luria-Bertani (LB) broth (BD Biosciences) at $37^{\circ} \mathrm{C}$ and $30^{\circ} \mathrm{C}$, respectively. M. luteus (ATCC no. 4698) was grown in Tryptic Soy media (BD Biosciences) at $37^{\circ} \mathrm{C}$ for 30 hours.

Bacterial suspensions for infections were prepared in PBS. Young and aged adult flies were infected with the bacteria (P. luminescens, $\mathrm{OD}_{600} 0.1$, $\sim 700 \mathrm{CFU}$; E. coli, $\mathrm{OD}_{600} 0.1, \sim 3,000 \mathrm{CFU}$; M. luteus, $\left.\mathrm{OD}_{600} 0.1, \sim 2,500 \mathrm{CFU}\right)$

through microinjection (64). PBS injections were used as negative controls. The number of dead flies was counted every 24 hours, and infection experiments were conducted in duplicate.

Infected and PBS-injected control flies were frozen 12 hours after infection. Total RNA isolation, cDNA synthesis, and quantitative real-time RTPCR were performed as previously described (64). Daw (CG16987) and Gbb (CG5562) transcription levels were normalized to the housekeeping gene RpL32 (CG7939) using the following primers: Daw forward, GGTGGATCAGCAGAAGGACT; Daw reverse, GCCACTGATCCAGTGTTTGA; Gbb forward, CCAGATGCAGACCCTGTACAT; Gbb reverse, GCCACTGATCCAGTGTTTGAA; RpL32 forward, GACGCTTCAAGGGACAGTATCTG; $R p L 32$ reverse, AAACGCGGTTCTGCATGAG. Relative mRNA abundance was calculated according to the $\Delta \Delta \mathrm{Ct}$ method (65). Data represent the ratio between infected and PBS-injected flies.

Statistics. Differences in percentage, absolute number, MFI, and parasite burden were evaluated using 2 -tailed Student's $t$ test. A $P$ value less than 0.05 was considered significant. Unless otherwise indicated, bar graphs represent mean \pm SD. For Supplemental Figure 11, bar graphs denote mean \pm SEM. Fly survival was calculated using Kaplan-Meier curves and log-rank analysis. Daw and Gbb mRNA levels in young and aged infected flies represent mean and SEM of relative values from 3 biological replicates. 2-tailed Student's $t$ test was performed to determine significant differences for Daw and Gbb transcription levels in young and aged flies. All statistical computations were performed using GraphPad Prism software.

Study approval. Animal studies were carried out in compliance with IACUC-approved guidelines at George Washington University Medical Center. For human studies, all participants were informed and consented to participate, and the study was reviewed and approved by the Ethical Committee of Virgen del Rocío University Hospital.

\section{Acknowledgments}

This work was supported by a NIH grant (AI-096978) to I.A. Khan as well as by Fondo de Investigaciones Sanitarias (CD10/00382), Redes Temáticas de Investigación en SIDA (ISCIII RETIC RD12/0017/0029 and RD12/0017/0037), Proyecto de Excelencia (CTS-6313), and Consejería de Salud (PI-0278) to M. Leal and S. Ferrando-Martinez. We thank Louis M. Weiss (Albert Einstein College of Medicine, New York, New York, USA) for critically reading the manuscript.

Received for publication April 17, 2013, and accepted in revised form February 24, 2014.

Address correspondence to: Imtiaz A. Khan, 2300 I Street N.W., Ross Hall Room 623, George Washington University, Washington, DC, 20037, USA. Phone: 202.994.2863; Fax: 202.994.2913; E-mail: imti56@gwu.edu.

1. Nikolich-Zugich J. The aging immune system: Challenges for the 21st century. Semin Immunol. 2012;24(5):301-302.

2. Nikolich-Zugich J. T cell aging: naive but not young. J Exp Med. 2005;201(6):837-840.

3. Yager EJ, Ahmed M, Lanzer K, Randall TD, Woodland DL, Blackman MA. Age-associated decline in $T$ cell repertoire diversity leads to holes in the repertoire and impaired immunity to influenza virus. J Exp Med. 2008;205(3):711-723.

4. Seder RA, Darrah PA, Roederer M. T-cell quality in memory and protection: implications for vaccine design. Nat Rev Immunol. 2008;8(4):247-258.

5. Precopio ML, et al. Immunization with vaccinia virus induces polyfunctional and phenotypically distinctive CD8(+) T cell responses. J Exp Med.
2007;204(6):1405-1416.

6. Betts MR, et al. HIV nonprogressors preferentially maintain highly functional HIV-specific CD8+ T cells. Blood. 2006;107(12):4781-4789.

7. Effros RB, et al. Aging and infectious diseases: workshop on HIV infection and aging: what is known and future research directions. Clin Infect Dis. 2008;47(4):542-553.

8. Didier ES, Weiss LM. Microsporidiosis: not just in AIDS patients. Curr Opin Infect Dis. 2011; 24(5):490-495

9. Lores B, Lopez-Miragaya I, Arias C, Fenoy S, Torres J, del Aguila C. Intestinal microsporidiosis due to Enterocytozoon bieneusi in elderly human immunodeficiency virus--negative patients from Vigo, Spain. Clin Infect Dis. 2002;34(7):918-921.
10. Nkinin SW, Asonganyi T, Didier ES, Kaneshiro ES. Microsporidian infection is prevalent in healthy people in Cameroon. J Clin Microbiol. 2007;45(9):2841-2846.

11. Sokolova OI, et al. Emerging microsporidian infections in Russian HIV-infected patients. JClin Microbiol. 2011;49(6):2102-2108

12. Mills EJ, Barnighausen T, Negin J. HIV and aging - preparing for the challenges ahead. NEngl J Med. 2012;366(14):1270-1273.

13. Balslev $U$, et al. Influence of age on rates of new AIDS-defining diseases and survival in 6546 AIDS patients. Scand J Infect Dis. 1997;29(4):337-343.

14. Moretto MM, Lawlor EM, Khan IA. Aging mice exhibit a functional defect in mucosal dendritic cell response against an intracellular pathogen. 
J Immunol. 2008;181(11):7977-7984.

15. Gigley JP, Khan IA. Plasmacytoid DC from aged mice down-regulate CD8 $\mathrm{T}$ cell responses by inhibiting cDC maturation after Encephalitozoon cuniculi infection. PLoS One. 2011;6(6):e20838.

16. Kaech SM, Tan JT, Wherry EJ, Konieczny BT, Surh $\mathrm{CD}$, Ahmed R. Selective expression of the interleukin 7 receptor identifies effector CD8 T cells that give rise to long-lived memory cells. Nat Immunol. 2003;4(12):1191-1198.

17. Haynes L, Eaton SM, Burns EM, Randall TD, Swain SL. Newly generated CD4 T cells in aged animals do not exhibit age-related defects in response to antigen. J Exp Med. 2005;201(6):845-851.

18. Bhadra R, Gigley JP, Khan IA. The CD8 T-cell road to immunotherapy of toxoplasmosis. Immunotherapy. 2011;3(6):789-801.

19. Shi Y, Massague J. Mechanisms of TGF-beta signaling from cell membrane to the nucleus. Cell. 2003;113(6):685-700.

20. Rudensky AY. Regulatory T cells and Foxp3. Immunol Rev. 2011;241(1):260-268.

21. Weant AE, Michalek RD, Khan IU, Holbrook BC, Willingham MC, Grayson JM. Apoptosis regulators Bim and Fas function concurrently to control autoimmunity and $\mathrm{CD}^{+} \mathrm{T}$ cell contraction. Immunity. 2008;28(2):218-230.

22. Li MO, Flavell RA. Contextual regulation of inflammation: a duet by transforming growth factor- $\beta$ and interleukin-10. Immunity. 2008;28(4):468-476.

23. Sanjabi S, Flavell RA. Overcoming the hurdles in using mouse genetic models that block TGF- $\beta$ signaling. J Immunol Methods. 2010;353(1-2):111-114.

24. Tinoco R, Alcalde V, Yang Y, Sauer K, Zuniga EI. Cell-intrinsic transforming growth factor-beta signaling mediates virus-specific CD8 $+\mathrm{T}$ cell deletion and viral persistence in vivo. Immunity. 2009;31(1):145-157.

25. Sanderson N, et al. Hepatic expression of mature transforming growth factor beta 1 in transgenic mice results in multiple tissue lesions. Proc Natl Acad Sci U S A. 1995;92(7):2572-2576.

26. Angelosanto JM, Wherry EJ. Transcription factor regulation of CD8+ T-cell memory and exhaustion. Immunol Rev. 2010;236:167-175

27. Kallies A, Xin A, Belz GT, Nutt SL. Blimp-1 transcription factor is required for the differentiation of effector CD8(+) T cells and memory responses. Immunity. 2009;31(2):283-295.

28. Rutishauser RL, et al. Transcriptional repressor Blimp-1 promotes CD8(+) T cell terminal differentiation and represses the acquisition of central memory $\mathrm{T}$ cell properties. Immunity. 2009;31(2):296-308.

29. Waterfield NR, Ciche T, Clarke D. Photorhabdus and a host of hosts. Annu Rev Microbiol. 2009;63:557-574.

30. Raftery LA, Sutherland DJ. TGF- $\beta$ family signal transduction in Drosophila development: from Mad to Smads. Dev Biol. 1999;210(2):251-268.

31. Sanjabi S, Mosaheb MM, Flavell RA. Opposing effects of TGF-beta and IL-15 cytokines control the number of short-lived effector $\mathrm{CD}^{+} \mathrm{T}$ cells. Immunity. 2009;31(1):131-144.
32. Messaoudi I, Lemaoult J, Guevara-Patino JA, Metzner BM, Nikolich-Zugich J. Age-related CD8 $\mathrm{T}$ cell clonal expansions constrict CD8 $\mathrm{T}$ cell repertoire and have the potential to impair immune defense. J Exp Med. 2004;200(10):1347-1358.

33. Nikolich-Zugich J. Ageing and life-long maintenance of T-cell subsets in the face of latent persistent infections. Nat Rev Immunol. 2008;8(7):512-522.

34. Rubinstein MP, et al. IL-7 and IL-15 differentially regulate $\mathrm{CD}^{+} \mathrm{T}$-cell subsets during contraction of the immune response. Blood. 2008;112(9):3704-3712.

35. Waller EC, McKinney N, Hicks R, Carmichael AJ, Sissons JG, Wills MR. Differential costimulation through CD137 (4-1BB) restores proliferation of human virus-specific "effector memory" (CD28(-) CD45RA(HI)) CD8(+) T cells. Blood. 2007;110(13):4360-4366.

36. Andersson A, et al. IL-7 promotes CXCR3 liganddependent $T$ cell antitumor reactivity in lung cancer. J Immunol. 2009;182(11):6951-6958.

37. Rizzo A, et al. Smad7 expression in T cells prevents colitis-associated cancer. Cancer Res. 2011;71(24):7423-7432.

38. Jung YW, Rutishauser RL, Joshi NS, Haberman AM, Kaech SM. Differential localization of effector and memory CD8 $\mathrm{T}$ cell subsets in lymphoid organs during acute viral infection. J Immunol. 2010;185(9):5315-5325.

39. Khan IA, Schwartzman JD, Kasper LH, Moretto $\mathrm{M}$. CD8 ${ }^{+}$CTLs are essential for protective immunity against Encephalitozoon cuniculi infection. J Immunol. 1999;162(10):6086-6091.

40. Clark RI, Woodcock KJ, Geissmann F, Trouillet C, Dionne MS. Multiple TGF- $\beta$ superfamily signals modulate the adult Drosophila immune response. Curr Biol. 2011;21(19):1672-1677.

41. Lawlor EM, Moretto MM, Khan IA. Optimal CD8 T-cell response against Encephalitozoon cuniculi is mediated by Toll-like receptor 4 upregulation by dendritic cells. Infect Immun. 2010;78(7):3097-3102.

42. Janssens S, Beyaert R. Role of Toll-like receptors in pathogen recognition. Clin Microbiol Rev. 2003;16(4):637-646.

43. Bouche M, Canipari R, Melchionna R, Willems $D$, Senni MI, Molinaro M. TGF- $\beta$ autocrine loop regulates cell growth and myogenic differentiation in human rhabdomyosarcoma cells. FASEB J. 2000;14(9):1147-1158.

44. Seki E, et al. TLR4 enhances TGF- $\beta$ signaling and hepatic fibrosis. Nat Med. 2007;13(11):1324-1332.

45. Rossi DJ, Jamieson CH, Weissman IL. Stems cells and the pathways to aging and cancer. Cell. 2008;132(4):681-696

46. Chen W, Konkel JE. TGF- $\beta$ and 'adaptive' Foxp3(+) regulatory T cells. J Mol Cell Biol. 2010;2(1):30-36.

47. Oldenhove G, et al. Decrease of Foxp3+ Treg cell number and acquisition of effector cell phenotype during lethal infection. Immunity. 2009;31(5):772-786.

48. Miyazono K. Shear activates platelet-derived latent TGF- $\beta$. Blood. 2008;112(9):3533-3534.

49. Shin $\mathrm{H}$, et al. A role for the transcriptional repressor Blimp-1 in CD8(+) T cell exhaustion during chronic viral infection. Immunity. 2009;31(2):309-320.
50. Morgan MA, et al. Blimp-1/Prdm1 alternative promoter usage during mouse development and plasma cell differentiation. Mol Cell Biol. 2009; 29(21):5813-5827.

51. Arsura M, Wu M, Sonenshein GE. TGF $\beta 1$ inhibits NF- $\kappa \mathrm{B} /$ Rel activity inducing apoptosis of $\mathrm{B}$ cells: transcriptional activation of IкB $\alpha$. Immunity. 1996;5(1):31-40.

52. Dorshkind K, Montecino-Rodriguez E, Signer RA. The ageing immune system: is it ever too old to become young again? Nat Rev Immunol. 2009;9(1):57-62.

53. Yoshikawa TT. Epidemiology and unique aspects of aging and infectious diseases. Clin Infect Dis. 2000;30(6):931-933.

54. Walsh KP, Brady MT, Finlay CM, Boon L, Mills $\mathrm{KH}$. Infection with a helminth parasite attenuates autoimmunity through TGF- $\beta$-mediated suppression of Th17 and Th1 responses. J Immunol. 2009;183(3):1577-1586

55. Borkow G, Bentwich Z. HIV and helminth co-infection: is deworming necessary? Parasite Immunol. 2006;28(11):605-612.

56. Brooker S, et al. Epidemiology of plasmodiumhelminth co-infection in Africa: populations at risk, potential impact on anemia, and prospects for combining control. Am J Trop Med Hyg. 2007; 77(6 suppl):88-98.

57. Mayer KD, et al. The functional heterogeneity of type 1 effector $\mathrm{T}$ cells in response to infection is related to the potential for IFN- $\gamma$ production. J Immunol. 2005;174(12):7732-7739.

58. Stetson DB, et al. Constitutive cytokine mRNAs mark natural killer (NK) and NK T cells poised for rapid effector function. J Exp Med. 2003;198(7):1069-1076.

59. Matsuda JL, et al. Mouse V alpha 14i natural killer $\mathrm{T}$ cells are resistant to cytokine polarization in vivo. Proc Natl Acad Sci U S A. 2003;100(14):8395-8400.

60. Ferrando-Martinez $S$, et al. Thymic function failure and C-reactive protein levels are independent predictors of all-cause mortality in healthy elderly humans. Age (Dordr). 2013;35(1):251-259.

61. Quezada SA, Peggs KS, Simpson TR, Shen Y, Littman DR, Allison JP. Limited tumor infiltration by activated $\mathrm{T}$ effector cells restricts the therapeutic activity of regulatory $T$ cell depletion against established melanoma. The Journal of experimental medicine. 2008;205(9):2125-2138.

62. Bhadra R, Gigley JP, Weiss LM, Khan IA. Control of Toxoplasma reactivation by rescue of dysfunctional CD8+ T-cell response via PD-1-PDL-1 blockade. Proc Natl Acad Sci U S A. 2011;108(22):9196-9201.

63. Weiss LM, Vossbrinck CR. Microsporidiosis: molecular and diagnostic aspects. Adv Parasitol. 1998;40:351-395.

64. Castillo JC, Shokal U, Eleftherianos I. Immune gene transcription in Drosophila adult flies infected by entomopathogenic nematodes and their mutualistic bacteria. J Insect Physiol. 2013;59(2):179-185.

65. Livak KJ, Schmittgen TD. Analysis of relative gene expression data using real-time quantitative PCR and the 2(-Delta Delta C(T)) Method. Methods. 2001;25(4):402-408 